\title{
2008/84
}

Characterizations of Pareto-efficient, fair, and strategy-proof allocation rules in queueing problems

Çağatay Kayı and Eve Ramaekers 
CORE

Voie du Roman Pays 34

B-1348 Louvain-la-Neuve, Belgium.

Tel (32 10) 474304

Fax (32 10) 474301

E-mail: corestat-library@uclouvain.be http://www.uclouvain.be/en-44508.html 


\title{
CORE DISCUSSION PAPER
}

$2008 / 84$

\section{Characterizations of Pareto-efficient, fair, and strategy-proof allocation rules in queueing problems}

\author{
Çağatay KAYI ${ }^{1}$ and Eve RAMAEKERS ${ }^{2}$
}

December 2008

\begin{abstract}
A set of agents with possibly different waiting costs have to receive the same service one after the other. Efficiency requires to maximize total welfare. Equity requires to at least treat equal agents equally. One must form a queue, set up monetary transfers to compensate agents having to wait, and not a priori arbitrarily exclude agents from positions. As one may not know agents' waiting costs, they may have no incentive to reveal them. We identify the only rule satisfying Paretoefficiency, a weak equity axiom as equal treatment of equals in welfare or symmetry, and strategyproofness. It satisfies stronger axioms, as no-envy and anonymity. Further, its desirability extends to related problems. To obtain these results, we prove that even non-single-valued rules satisfy Pareto-efficiency of queues and strategy-proofness if and only if they select Pareto-efficient queues and set transfers in the spirit of Groves (1973). This holds in other problems, provided the domain of quasi-linear preferences is rich enough.
\end{abstract}

Keywords: queueing problems, efficiency, fairness, strategy-proofness.

JEL Classification: D63, C72

\footnotetext{
${ }^{1}$ Maastricht University, Department of Economics, The Netherlands.

${ }^{2}$ Chargé de recherches du F.R.S.-FNRS; Université catholique de Louvain, CORE, B-1348 Louvain-laNeuve, Belgium. E-mail: eve.ramaekers@uclouvain.be.

We thank Paulo Barelli, Walter Bossert, Philippe Chevalier, Santanu Dey, François Maniquet, Manipushpak Mitra, Hervé Moulin, Hans Peters, Jay Sethuraman, William Thomson, Gábor Virág, seminar participants at the University of Maastricht, Social Choice and Welfare Conference 2006, University of Rochester, and two anonymous referees for helpful discussions, comments, or suggestions.

This paper presents research results of the Belgian Program on Interuniversity Poles of Attraction initiated by the Belgian State, Prime Minister's Office, Science Policy Programming. The scientific responsibility is assumed by the authors.
} 



\section{Introduction}

Consider an ice storm in Rochester, NY. After the storm, many business firms urge for individual repair of their electrical systems at the same time. Rochester Gas and Electric eventually provides the repair service in each firm. Yet, each firm having to wait, incurs a cost that linearily increases with time, namely its hourly loss of revenue.

In such a situation, agents must queue. One may a priori recommend several queues and may set up monetary transfers. Efficiency requires to maximize total welfare. Equity requires to treat equal agents equally. As one may not know agents' waiting costs, they may have no incentive to reveal them.

Our objective is to identify solutions to such queueing problems satisfying the following axioms. First is Pareto-efficiency. On the domain of linear preferences in transfers, we can decompose it into two distinct axioms, Paretoefficiency of queues, i.e. queues should minimize total waiting cost, and balancedness, i.e. transfers should sum up to zero.

Second, we should treat agents with equal waiting costs equally. As we cannot serve agents simultaneously, we cannot give two agents with equal waiting costs equal positions. Yet, using transfers, we can compensate the agent having to wait. Selecting more than one queue, we can avoid a priori arbitrarily excluding an agent from the position of the other. We impose equal treatment of equals in welfare, i.e. agents with equal waiting costs should have equal welfares, and symmetry, i.e. agents with equal waiting costs should have the possibility to receive the same bundles.

Both axioms are important. In particular, they are necessary conditions for axioms embodying further basic equity criteria. No-envy, i.e. no agent should prefer another agent's bundle to her own, implies the former. Anonymity, i.e. agents' names should not matter, implies the latter. A priori recommending not more than one way to allocate positions and transfers, we may satisfy equal treatment of equals in welfare, not symmetry. Thus, because we cannot serve agents simultaneously, anonymity is possible if and only if we allow selecting more than one allocation.

Third is strategy-proofness, i.e. each agent should find revealing her unit waiting cost at least as desirable as misrepresenting it. The impossibility to serve agents simultaneously and equity impose allowing to select more than one allocation. Agents compare non-empty sets of allocations. We assume that an agent finds such a set as desirable as another if and only if she finds $(i)$ the worst bundle she may receive from the former as desirable as the worst bundle she may from the latter, and ( $i i)$ the worst bundle she may receive from the former as desirable as the worst bundle she may from the latter. 
We identify the only allocation rule satisfying these axioms on the domain of linear preferences in positions and transfers. For each problem, it selects all Pareto-efficient queues and sets transfers considering each pair of agents in turn, making each agent in the pair pay the cost she imposes on the pair, and distributing the sum of these two payments equally among the others. We refer to it as the Largest Equally Distributed Pairwise Pivotal (LEDPP) rule. Further, we prove that it satisfies no-envy, anonymity, and stronger incentive compatibility criteria. Indeed, it is such that each agent always finds any bundle she receives when revealing her unit waiting cost at least as desirable as any bundle she receives when misrepresenting it.

To reach our objective, we first characterize the class of rules satisfying Paretoefficiency of queues and strategy-proofness. In such queueing problems, as in any public decision-making problem with additively separable preferences with respect to transfers, there are single-valued rules satisfying these axioms (Groves, 1973). Also, as in any public decision-making problem with convex preferences, only these single-valued rules satisfy them (Holmström, 1979). ${ }^{2}$ Yet, for the cases where equity considerations make multiple choices compelling, or simply for a concern to a priori impose the least, one need not want to impose single-valuedness.

We prove that even a non-single-valued rule satisfies Pareto-efficiency of queues and strategy-proofness if and only if for each problem, it selects Paretoefficient queues and it sets each agent's transfer in the spirit of Groves (1973). Indeed, for each bundle that maximizes or minimizes her utility, her transfer is equal to the others' total waiting cost plus an amount only depending on these agents' unit waiting costs. This characterization holds in public decisionmaking problems other than the queueing problems we study, provided the domain of quasi-linear preferences is rich enough.

Second, we identify the class of rules satisfying Pareto-efficiency, equal treatment of equals in welfare, and strategy-proofness. We prove that one of these rules, the LEDPP rule, is the only rule satisfying Pareto-efficiency, symmetry, and strategy-proofness. Thus, while Pareto-efficiency and strategy-proofness leave us with a large class of rules, adding a weak equity axiom as equal treatment of equals in welfare or symmetry, imposes a unique transfers list. One also obtains it following Suijs (1996), Mitra and Sen (1998), and Mitra (2001).

The intuition for this characterization is simple. We obtain any rule that satisfies Pareto-efficiency of queues and strategy-proofness, selecting the Paretoefficient queues appropriately and setting each agent's transfer equal to the

$\overline{2}$ Holmström (1979) proves this result on the domain of public decision-making problems with smoothly connected preferences, i.e. for any two profiles in the domain, there is a differentiable deformation of one profile into the other that is also in the domain. Green and Laffont (1977) prove it on the universal domain. 
cost she imposes on the others plus an appropriately chosen amount that only depends on the others' waiting costs. By balancedness, a desirable rule redistributes these costs' sum. ${ }^{3}$ By equity, it selects all Pareto-efficient queues and it redistributes this sum fairly. By strategy-proofness, it redistributes this sum, so that each agent's share only depends on the others' waiting costs.

This is exactly what the LEDPP rule does. It selects all Pareto-efficient queues (so it is efficient and fair). It sets each agent's transfer considering each pair of agents in turn, making each agent in the pair pay the cost she imposes on the pair, and distributing the sum of these two payments (so it is efficient) equally (so it is fair) among the others (so it is strategy-proof).

The framework's key feature, on which we build this rule, is as follows. We can express the sum of the costs each agent imposes on the others, i.e. the sum that Pareto-efficiency of queues, strategy-proofness, and balancedness impose to redistribute, as the sum of the costs each agent imposes on each element of a partition of the others. This is what makes these axioms and equity compatible in the particular queueing problems we study, not in others. ${ }^{4}$

We conjecture that in general public decision-making problems with additively separable preferences with respect to transfers, in which we can express the sum of welfare changes each agent imposes on the others likewise, this compatibility be possible. In particular, the appropriate generalization of the LEDPP rule should still satisfy these axioms, if not still be the only one. It is true in queueing problems, in which agents enjoy some benefit once they receive the service; in queueing problems, in which agents may differ in processing times; and in assignment problems of at most one indivisible good per agent, in which agents rank goods identically. (See Extensions.)

The allocation problems we study are thus among the few, in which Pareto-

3 As each of these costs is always greater or equal to zero, with equality holding only for the last agent in the queue, their sum is always strictly positive.

4 In public decision-making problems with additively separable preferences with respect to transfers, Pareto-efficiency of queues and strategy-proofness imply transfers that need not sum to zero and hence, an incompatibility with balancedness (Green and Laffont, 1977). In queueing problems with linear preferences in transfers, combinatorial and independence conditions over the structure of waiting costs are necessary and sufficient for these axioms' compatibility (Mitra and Sen, 1998; Mitra, 2001, 2002). For instance, if preferences are also linear in positions, there are rules satisfying these axioms (Suijs, 1996; Mitra and Sen, 1998). The combinatorial condition requires each agent to always have her $(n-1)$ th order difference of waiting costs at the first position in the queue equal to zero, where $n$ is the number of agents. The independence condition requires that if an agent precedes another in a Pareto-efficient queue and a third agent leaves, the former should still precedes the other in a Pareto-efficient queue for the reduced problem. 
efficiency, equity, and strategy-proofness are compatible. In general social choice problems, no equity axiom is compatible with strategy-proofness (Gibbard, 1973; Satterthwaite, 1975). If rules satisfy equity axioms and strategyproofness in restricted classes of problems, they violate Pareto-efficiency.

The other exceptions are as follows. In allocation problems of a public good chosen in an interval, over which preferences are continuous and single-peaked, only the Generalized Condorcet rules satisfy Pareto-efficiency, anonymity, and strategy-proofness (Moulin, 1980). ${ }^{5}$ In allocation problems of infinitely divisible goods, in which preferences are continuous and single-peaked, only the Uniform rule satisfies Pareto-efficiency, equal treatment of equals in welfare, and strategy-proofness, as well as Pareto-efficiency, symmetry, and strategyproofness (Sprumont, 1991; Ching, 1994). ${ }^{6}$ In allocation problems of infinitely divisible goods produced by a linear technology, only the Equal Income Walrasian rule satisfies Pareto-efficiency, equal treatment of equals in welfare, and strategy-proofness (Maniquet and Sprumont, 1999).

The allocation problems we study distinguish themselves from the former ones. When allocating a public good or an infinitely divisible good, we can give equal agents equal bundles. Then, equal treatment of equals in welfare is equivalent to symmetry. In queueing problems, as we cannot serve agents simultaneously, it is not the case. Then, efficiency, equity, and incentive compatibility simultaneously may still produce ties. A solution satisfying such criteria hence differs from the former ones. In particular, it should not a priori arbitrarily break these ties, instead allow multiple choices.

In Section 2, we formally introduce the model. In Section 3, we define the axioms we impose on rules. In Section 4, we identify the only rule satisfying these axioms. We prove it satisfies further axioms. In Section 5, we discuss extensions of the problems we study. Finally, we give concluding comments.

\section{Model}

There is a finite set of agents $N$. Let $n=|N|$. Each agent $i \in N$ may consume a position $\sigma_{i} \in \mathbb{N}$ in a queue and a positive or negative transfer $t_{i} \in \mathbb{R}$.

5 The Generalized Condorcet rule associated with a list of $(n-1)$ parameters in the interval, always selects the median of these parameters and the agents' peaks.

6 The Uniform rule always selects its allocation as follows. If the sum of the agents' peaks is greater or equal to the amount of goods available, an agent receives her peak if it is smaller than a common bound, otherwise she receives this bound, chosen so the allocation is feasible. If the sum of the agents' peaks is less or equal to the amount of goods available, she receives her peak if it is greater than a common bound, otherwise she receives this bound, chosen so the allocation is feasible. 
Preferences are linear in position and transfer. Let $c_{i} \in \mathbb{R}_{++}$be the unit waiting cost of $i \in N$. If $i$ is served $\sigma_{i}$-th, her total waiting cost is $\left(\sigma_{i}-1\right) c_{i}$. We can represent her preferences by the following function: for each $\left(\sigma_{i}, t_{i}\right) \in \mathbb{N} \times \mathbb{R}$, we have $u\left(\sigma_{i}, t_{i} ; c_{i}\right)=-\left(\sigma_{i}-1\right) c_{i}+t_{i}$. For each $\left(\sigma_{i}, t_{i}\right) \in \mathbb{N} \times \mathbb{R}$, we use the following notational shortcut. For $c_{i} \in \mathbb{R}_{++}$, let $u_{i}\left(\sigma_{i}, t_{i}\right) \equiv u\left(\sigma_{i}, t_{i} ; c_{i}\right)$; for $c_{i}^{\prime} \in \mathbb{R}_{++}$, let $u_{i}^{\prime}\left(\sigma_{i}, t_{i}\right) \equiv u\left(\sigma_{i}, t_{i} ; c_{i}^{\prime}\right)$; and so on. A (queueing) problem is a list $c \equiv\left(c_{i}\right)_{i \in N} \in \mathbb{R}_{++}^{N}$.

An allocation is a pair $(\sigma, t) \equiv\left(\sigma_{i}, t_{i}\right)_{i \in N} \in(\mathbb{N} \times \mathbb{R})^{N}$ such that $(i)$ for each pair of agents, their positions in queue $\sigma$ differ, i.e. for each $\{i, j\} \subset N$ with $i \neq j$, we have $\sigma_{i} \neq \sigma_{j}$, and $(i i)$ the sum of transfers $t$ is non-positive, i.e. $\sum_{i \in N} t_{i} \leq 0$. Let $Z$ be the set of all allocations. An (allocation) rule $\varphi$ is a correspondence that associates with each problem $c \in \mathbb{R}_{++}^{N}$ a non-empty set of allocations $\varphi(c) \subseteq Z$.

We end this section with some more notation. For $S \subseteq N$, let $\bar{\Sigma}(S) \equiv$ $\left\{\left(\sigma_{i}\right)_{i \in S} \in \mathbb{N}^{S} \mid\right.$ for each $i, j \in S$ with $i \neq j$, we have $\left.\sigma_{i} \neq \sigma_{j}\right\}$. For $\sigma \in \bar{\Sigma}(N)$ and $i \in N$, let $P_{i}(\sigma) \equiv\left\{j \in N \mid \sigma_{j}<\sigma_{i}\right\}$ be the set of all agents preceding $i$ in $\sigma$ and $F_{i}(\sigma) \equiv\left\{j \in N \mid \sigma_{j}>\sigma_{i}\right\}$ be the set of all agents following $i$ in $\sigma$. For $j \in N \backslash\{i\}$, let $B_{i j}(\sigma) \equiv\left\{l \in N \mid \min \left\{\sigma_{i}, \sigma_{j}\right\}<\sigma_{l}<\max \left\{\sigma_{i}, \sigma_{j}\right\}\right\}$ be the set of all agents served between $i$ and $j$ in $\sigma$. Let $\mathcal{Z}$ be the set of all non-empty sets of allocations. For $c_{i} \in \mathbb{R}_{++}$and $X \in \mathcal{Z}$, let $\min u_{i}(X) \equiv \min _{(\sigma, t) \in X} u_{i}\left(\sigma_{i}, t_{i}\right)$, let $\arg \min u_{i}(X) \equiv\left\{(\sigma, t) \in X \mid u_{i}\left(\sigma_{i}, t_{i}\right)=\min u_{i}(X)\right\}$, and likewise for $\max u_{i}(X)$ and $\arg \max u_{i}(X)$. For $c \in \mathbb{R}_{++}^{N}$, let $c_{-i} \equiv\left(c_{l}\right)_{l \in N \backslash\{i\}}$ be the list of the unit waiting costs of $N \backslash\{i\}$.

\section{Properties of rules}

In this section, we define the axioms we impose on rules. Let $\varphi$ be a rule.

Efficiency is standard. There should be no allocation each agent finds at least as desirable as a selected allocation and at least one agent prefers. Formally,

Pareto-efficiency: For each $c \in \mathbb{R}_{++}^{N}$ and each $(\sigma, t) \in \varphi(c)$, there is no $\left(\sigma^{\prime}, t^{\prime}\right) \in Z$ such that for each $i \in N$, we have $u_{i}\left(\sigma_{i}^{\prime}, t_{i}^{\prime}\right) \geq u_{i}\left(\sigma_{i}, t_{i}\right)$ and for at least one $j \in N$, we have $u_{j}\left(\sigma_{j}^{\prime}, t_{j}^{\prime}\right)>u_{j}\left(\sigma_{j}, t_{j}\right)$.

Remark that $(\sigma, t) \in Z$ is Pareto-efficient for $c \in \mathbb{R}_{++}^{N}$ if and only if $(i) \sigma$ is Pareto-efficient for $c$, i.e. for each $\sigma^{\prime} \in \bar{\Sigma}(N)$, we have $\sum_{i \in N}\left(\sigma_{i}^{\prime}-1\right) c_{i} \geq$ $\sum_{i \in N}\left(\sigma_{i}-1\right) c_{i}$, and $(i i) t$ is balanced, i.e. $\sum_{i \in N} t_{i}=0$. Thus, queues minimize the agents' total waiting cost independently of transfers. Such queues are unique up to any permutation of agents with equal unit waiting costs following 
one another. Let $\bar{\Sigma}^{*}(c)$ be the set of all Pareto-efficient queues for $c$. For each $c \in \mathbb{R}_{++}^{N}$ and each $(\sigma, t) \in Z$, we have $\sigma \in \bar{\Sigma}^{*}(c)$ if and only if for each $\{i, j\} \subset N$ with $i \neq j$, if $\sigma_{i}<\sigma_{j}$, then $c_{i} \geq c_{j}$. Following this remark, we decompose Pareto-efficiency into two axioms.

Pareto-efficiency of queues: For each $c \in \mathbb{R}_{++}^{N}$ and each $(\sigma, t) \in \varphi(c)$, we have $\sigma \in \bar{\Sigma}^{*}(c)$.

Balancedness: For each $c \in \mathbb{R}_{++}^{N}$ and each $(\sigma, t) \in \varphi(c)$, we have $\sum_{i \in N} t_{i}=0$.

Equity requires to treat agents with equal unit waiting costs equally. As we cannot serve agents simultaneously, we cannot give two agents with equal unit waiting costs equal bundles. We require agents with equal unit waiting costs to have equal welfares and to be treated symmetrically, i.e. if there is an allocation different from a selected allocation in that we exchange the bundles of two of such agents and keep the bundles of the others unchanged, it should be selected. Formally,

Equal treatment of equals in welfare: For each $c \in \mathbb{R}_{++}^{N}$, each $(\sigma, t) \in$ $\varphi(c)$, and each $\{i, j\} \subset N$ with $i \neq j$ and $c_{i}=c_{j}$, we have $u_{i}\left(\sigma_{i}, t_{i}\right)=u_{j}\left(\sigma_{j}, t_{j}\right)$.

Symmetry: For each $c \in \mathbb{R}_{++}^{N}$, each $(\sigma, t) \in \varphi(c)$, and each $\{i, j\} \subset N$ with $i \neq j$ and $c_{i}=c_{j}$, if $\left(\sigma^{\prime}, t^{\prime}\right) \in Z$ such that $\left(\sigma_{i}^{\prime}, t_{i}^{\prime}\right)=\left(\sigma_{j}, t_{j}\right),\left(\sigma_{j}^{\prime}, t_{j}^{\prime}\right)=\left(\sigma_{i}, t_{i}\right)$, and for each $l \in N \backslash\{i, j\}$, we have $\left(\sigma_{l}^{\prime}, t_{l}^{\prime}\right)=\left(\sigma_{l}, t_{l}\right)$, then $\left(\sigma^{\prime}, t^{\prime}\right) \in \varphi(c)$.

Both axioms are important. In particular, axioms embodying further basic equity criteria imply them. Equal treatment of equals in welfare is necessary for no agent to prefer another agent's bundle to her own. Symmetry is necessary for agents' names not to matter. This second axiom requires that if we permute agents' unit waiting costs, we should permute the selected bundles accordingly. Formally, let $\Pi$ be the set of all permutations on $N$. For $\pi \in \Pi$ and $c \in \mathbb{R}^{N}$, let $\pi(c) \equiv\left(c_{\pi(i)}\right)_{i \in N}$ and $\pi(\sigma, t) \equiv\left(\sigma_{\pi(i)}, t_{\pi(i)}\right)_{i \in N}$.

No-envy: For each $c \in \mathbb{R}_{++}^{N}$, each $(\sigma, t) \in \varphi(c)$, and each $i \in N$, there is no $j \in N \backslash\{i\}$ such that $u_{i}\left(\sigma_{j}, t_{j}\right)>u_{i}\left(\sigma_{i}, t_{i}\right)$.

Anonymity: For each $c \in \mathbb{R}_{++}^{N}$, each $(\sigma, t) \in \varphi(c)$, and each $\pi \in \Pi$, we have $\pi(\sigma, t) \in \varphi(\pi(c))$.

Single-valued and non-single-valued rules may satisfy equal treatment of equals in welfare. Yet, no single-valued rule satisfies symmetry. Thus, because we 
cannot serve agents simultaneously, we may impose anonymity if and only if we allow rules to select more than one allocation.

Strategic considerations motivate the last axiom. We may not know agents' unit waiting costs. As agents may behave strategically when announcing them, we may not attain efficiency nor equity. We require each agent to find revealing her unit waiting cost as desirable as misrepresenting it.

As rules may select more than one allocation, a strategic agent compares nonempty sets of allocations. It is crucial to determine this comparison's outcomes. The agent's preferences are defined on the set of positions and transfers. It is not immediate how these preferences and her preferences on the set of nonempty sets of allocations relate. Yet, selecting a multi-valued set of allocations is a first step. By definition, the allocations it contains are mutually exclusive. In fine, only one materializes. Thus, the comparison's outcomes depend on the agent's predictions regarding how, when a rule produces such a tie, it is broken, and on her aversion toward the uncertainty such a context involves.

Given the equity considerations guiding our analysis, we assume the tiebreaker to be at least a random device. We assume the agents know it. Besides, as allocations are mutually exclusive, we assume each agent's preferences on the set of non-empty sets of allocations extend her preferences on the set of allocations, in the sense that her singletons' ranking matches her original ranking. ${ }^{7}$ Then, each plausible extension of an agent's preferences on the set of allocations to the set of non-empty sets of allocations is entirely determined by her ranking of these sets' best and worst elements (Kannai and Peleg, 1984). ${ }^{8}$ Further, if the agent is neutral with respect to allocations' names, there is only one such extension that is as follows (Bossert, 1989).

An agent finds a non-empty set of allocations as desirable as another if and only if she finds $(i)$ the worst bundle she may receive from the former as desirable as the worst bundle she may from the latter, and (ii) the worst

\footnotetext{
7 In any social choice problem with mutually exclusive alternatives, it is natural to assume that each agent's preferences on the set of non-empty sets of alternatives is an extension of her preferences on the set of alternatives. Then, from the many possible tiebreaker predictions and uncertainty aversions, there are many possible such extensions. See e.g. Fishburn (1972), Pattanaik (1973), Gärdenfors (1976, 1979), Barberá (1977), Kelly (1977), Feldman (1979), Duggan and Schwartz (2000), Barberá et al. (2001), and Ching and Zhou (2002).

8 Plausible in the problem we study, as their result holds under the following assumptions. Preferences on the set of alternatives are an ordering on this set. They include a linear ordering on a subset of at least six alternatives. Preferences on the set of non-emtpy sets of alternatives is a quasi-ordering on this set. They may embody any attitude toward uncertainty, but extreme ones. They do not reveal complementarity type relationships between alternatives.
} 
bundle she may receive from the former as desirable as the worst bundle she may from the latter. Formally, for $c_{i} \in \mathbb{R}_{++}$, let $R_{i}\left(c_{i}\right)$ be such that for each $X, X^{\prime} \in \mathcal{Z}$, we have $X R_{i}\left(c_{i}\right) X^{\prime}$ if and only if $\min u_{i}(X) \geq \min u_{i}\left(X^{\prime}\right)$ and $\max u_{i}(X) \geq \max u_{i}\left(X^{\prime}\right)$. Then,

Strategy-proofness: For each $c \in \mathbb{R}_{++}^{N}$, each $i \in N$, and each $c_{i}^{\prime} \in \mathbb{R}_{++}$, we have $\varphi(c) R_{i}\left(c_{i}\right) \varphi\left(c_{i}^{\prime}, c_{-i}\right)$.

We end this section with two remarks on this axiom. First, a single-valued rule satisfies it if and only if for each $c \in \mathbb{R}_{++}^{N}$, each $i \in N$, and each $c_{i}^{\prime} \in \mathbb{R}_{++}$, if $(\sigma, t)=\varphi(c)$ and $\left(\sigma^{\prime}, t^{\prime}\right)=\varphi\left(c_{i}^{\prime}, c_{-i}\right)$, then $u_{i}\left(\sigma_{i}, t_{i}\right) \geq u_{i}\left(\sigma_{i}^{\prime}, t_{i}^{\prime}\right)$.

Second, as e.g. in Pattanaik (1973), it requires each agent to find the worst bundle she may receive when revealing her unit waiting cost at least as desirable as the worst bundle she may receive when misrepresenting it. As e.g. in Feldman (1979), it requires each agent to find the best bundle she may receive when revealing her unit waiting cost at least as desirable as the best bundle she may receive when misrepresenting it. This second requirement is a necessary condition for further basic incentive compatibility criteria, in particular for rules to be implementable in undominated strategies by bounded mechanisms (Jackson, 1992) and for each agent not to find misrepresenting her unit waiting cost more desirable than revealing it via addition or deletion of allocations (Ching and Zhou, 2002). ${ }^{9}$

\section{Characterizations}

In this section, we identify the only rule satisfying the axioms we impose. Further, we prove that it satisfies no-envy, anonymity, and stronger incentive compatibility criteria. Indeed, it is such that each agent always finds any bundle she receives when revealing her unit waiting cost at least as desirable as any bundle she receives when misrepresenting it.

Therefore, we characterize the class of rules satisfying Pareto-efficiency of queues and strategy-proofness (Theorem 1). Then, we identify the class of rules satisfying Pareto-efficiency, equal treatment of equals in welfare, and strategy-proofness and we prove that these rules satisfy no-envy (Theorem 3, Statements 1 and 2). Finally, we prove that one of these rules is the only

$\overline{9}$ Formally, an agent does not find misrepresenting her unit waiting cost more desirable as revealing it via addition or deletion of allocations if there is no $c \in \mathbb{R}_{++}^{N}$, $i \in N$, and $c_{i}^{\prime} \in \mathbb{R}_{++}$such that for $(\sigma, t) \in \varphi\left(c_{i}^{\prime}, c_{-i}\right) \backslash \varphi(c)$, we have $u_{i}\left(\sigma_{i}, t_{i}\right)>$ $\min u_{i}(\varphi(c))$ or for $(\sigma, t) \in \varphi(c) \backslash \varphi\left(c_{i}^{\prime}, c_{-i}\right)$, we have $\max u_{i}\left(\varphi\left(c_{i}^{\prime}, c_{-i}\right)\right)>u_{i}\left(\sigma_{i}, t_{i}\right)$. 
rule satisfying Pareto-efficiency, symmetry, and strategy-proofness, and that it satisfies anonymity (Theorem 3, Statements 3 and 4).

We begin by proving that a rule satisfies Pareto-efficiency of queues and strategy-proofness if and only if for each problem, it selects Pareto-efficient queues and it sets each agent's transfer in the spirit of Groves (1973). Indeed, for each bundle that maximizes or minimizes her utility, her transfer is equal to the others' total waiting cost plus an amount only depending on these agents' unit waiting costs.

The intuition is as follows. Assume that is not the case and that if an agent with some waiting cost announces some other waiting cost, the change in her utility would be greater (smaller) than the efficiency loss. Then, there would always be a waiting cost for which she should receive the same position and transfer as with the latter (former) waiting cost and for which announcing the former (latter) waiting cost would increase her utility. We apply this rationale first to the selected bundles that are the arguments of the utility maximum, then to those that are the arguments of the utility minimum. Yet, the proof is not symmetric. In the latter case, we must use a neighborhood argument.

Formally, let $D$ be the set of all correspondences that associate with each $c \in \mathbb{R}_{++}^{N}$ a non-empty set of Pareto-efficient queues for $c$, i.e. for each $d \in D$ and each $c \in \mathbb{R}_{++}^{N}$, we have $d(c) \neq \emptyset$ and $d(c) \subseteq \bar{\Sigma}^{*}(c)$. Let $H$ be the set of all lists of functions that associate with each $i \in N$ and each $c_{-i} \in \mathbb{R}_{++}^{N \backslash\{i\}}$ a real number, i.e. for each $\left(h_{i}\right)_{i \in N} \in H$, each $i \in N$, and each $c_{-i} \in \mathbb{R}_{++}^{N \backslash\{i\}}$, we have $h_{i}\left(c_{-i}\right) \in \mathbb{R}$. A rule $\varphi$ is a Groves rule if and only if there are $d \in D$ and $\{\underline{h}, \bar{h}\} \subset H$ such that for each $c \in \mathbb{R}_{++}^{N},(i) d(c) \equiv\left\{\sigma \in \bar{\Sigma}(N) \mid\right.$ there is $t \in \mathbb{R}^{N}$ such that $(\sigma, t) \in \varphi(c)\}$ and $(i i)$ for each $i \in N$, if $(\sigma, t) \in \arg \min u_{i}(\varphi(c))$, then $t_{i}=-\sum_{l \in N \backslash\{i\}}\left(\sigma_{l}-1\right) c_{l}+\underline{h}_{i}\left(c_{-i}\right)$ and if $(\sigma, t) \in \arg \max u_{i}(\varphi(c))$, then $t_{i}=-\sum_{l \in N \backslash\{i\}}\left(\sigma_{l}-1\right) c_{l}+\bar{h}_{i}\left(c_{-i}\right)$.

Theorem 1 Let $\varphi$ be a rule. Then, $\varphi$ satisfies Pareto-efficiency of queues and strategy-proofness if and only if it is a Groves rule.

\section{Proof.}

Part 1: If $\varphi$ is a Groves rule, then it satisfies Pareto-efficiency of queues and strategy-proofness.

Pareto-efficiency of queues: Assume that $\varphi$ is a Groves rule. By definition, there is $d \in D$ such that for each $c \in \mathbb{R}_{++}^{N}$, if $(\sigma, t) \in \varphi(c)$, then $\sigma \in d(c) \subseteq$ $\bar{\Sigma}^{*}(c)$.

Strategy-proofness: Assume that $\varphi$ is a Groves rule. By definition, there is $d \in D$ such that (i) for each $c \in \mathbb{R}_{++}^{N}$, if $(\sigma, t) \in \varphi(c)$, then $\sigma \in d(c) \subseteq \bar{\Sigma}^{*}(c)$. Also, there is $\{\underline{h}, \bar{h}\} \subset H$ such that (ii) for each $c \in \mathbb{R}_{++}^{N}$ and each $i \in N$, 
- if $(\sigma, t) \in \arg \min u_{i}(\varphi(c))$, then $t_{i}=-\sum_{l \in N \backslash\{i\}}\left(\sigma_{l}-1\right) c_{l}+\underline{h}_{i}\left(c_{-i}\right)$;

- if $(\sigma, t) \in \arg \max u_{i}(\varphi(c))$, then $t_{i}=-\sum_{l \in N \backslash\{i\}}\left(\sigma_{l}-1\right) c_{l}+\bar{h}_{i}\left(c_{-i}\right)$.

Let $c \in \mathbb{R}_{++}^{N}, i \in N$, and $c_{i}^{\prime} \in \mathbb{R}_{++}$. Then, the following holds.

(iii) For each $(\sigma, t) \in \arg \min u_{i}(\varphi(c))$, we have $u_{i}\left(\sigma_{i}, t_{i}\right) \geq \min u_{i}\left(\varphi\left(c_{i}^{\prime}, c_{-i}\right)\right)$. Indeed, let $(\sigma, t) \in \arg \min u_{i}(\varphi(c))$ and $\left(\sigma^{\prime}, t^{\prime}\right) \in \arg \min u_{i}^{\prime}\left(\varphi\left(c_{i}^{\prime}, c_{-i}\right)\right)$. By $(\mathbf{i}),-\sum_{l \in N}\left(\sigma_{l}-1\right) c_{l} \geq-\sum_{l \in N}\left(\sigma_{l}^{\prime}-1\right) c_{l}$. Thus, $-\left(\sigma_{i}-1\right) c_{i}-\sum_{l \in N \backslash\{i\}}\left(\sigma_{l}-\right.$ 1) $c_{l}+\underline{h}_{i}\left(c_{-i}\right) \geq-\left(\sigma_{i}^{\prime}-1\right) c_{i}-\sum_{l \in N \backslash\{i\}}\left(\sigma_{l}^{\prime}-1\right) c_{l}+\underline{h}_{i}\left(c_{-i}\right) . B y(\mathbf{i i}), u_{i}\left(\sigma_{i}, t_{i}\right) \geq$ $u_{i}\left(\sigma_{i}^{\prime}, t_{i}^{\prime}\right)$. By assumption, $u_{i}\left(\sigma_{i}^{\prime}, t_{i}^{\prime}\right) \geq \min u_{i}\left(\varphi\left(c_{i}^{\prime}, c_{-i}\right)\right)$. Thus, $u_{i}\left(\sigma_{i}, t_{i}\right) \geq$ $\min u_{i}\left(\varphi\left(c_{i}^{\prime}, c_{-i}\right)\right)$.

(iv) For each $(\sigma, t) \in \arg \max u_{i}(\varphi(c))$, we have $u_{i}\left(\sigma_{i}, t_{i}\right) \geq \max u_{i}\left(\varphi\left(c_{i}^{\prime}, c_{-i}\right)\right)$. Indeed, let $(\sigma, t) \in \arg \max u_{i}(\varphi(c))$ and $\left(\sigma^{\prime}, t^{\prime}\right) \in \arg \max u_{i}^{\prime}\left(\varphi\left(c_{i}^{\prime}, c_{-i}\right)\right)$. Let $(\tilde{\sigma}, \tilde{t}) \in \arg \max u_{i}\left(\varphi\left(c_{i}^{\prime}, c_{-i}\right)\right)$ and $g_{i}\left(c_{i}^{\prime}, c_{-i}\right) \in \mathbb{R}$ be such that $\tilde{t}_{i}=$ $-\sum_{l \in N \backslash\{i\}}\left(\tilde{\sigma}_{l}-1\right) c_{l}+g_{i}\left(c_{i}^{\prime}, c_{-i}\right)$. By assumpion, $u_{i}^{\prime}\left(\sigma_{i}^{\prime}, t_{i}^{\prime}\right) \geq u_{i}^{\prime}\left(\tilde{\sigma}_{i}, \tilde{t}_{i}\right)$. By (ii), $-\left(\sigma_{i}^{\prime}-1\right) c_{i}^{\prime}-\sum_{l \in N \backslash\{i\}}\left(\sigma_{l}^{\prime}-1\right) c_{l}+\bar{h}_{i}\left(c_{-i}\right) \geq-\left(\tilde{\sigma}_{i}-1\right) c_{i}^{\prime}-\sum_{l \in N \backslash\{i\}}\left(\tilde{\sigma}_{l}-1\right) c_{l}+$ $g_{i}\left(c_{i}^{\prime}, c_{-i}\right) . B y(\mathbf{i}),-\left(\sigma_{i}^{\prime}-1\right) c_{i}^{\prime}-\sum_{l \in N \backslash\{i\}}\left(\sigma_{l}^{\prime}-1\right) c_{l}=-\left(\tilde{\sigma}_{i}-1\right) c_{i}^{\prime}-\sum_{l \in N \backslash\{i\}}\left(\tilde{\sigma}_{l}-\right.$ 1) $c_{l}$. Thus, $\bar{h}_{i}\left(c_{-i}\right) \geq g_{i}\left(c_{i}^{\prime}, c_{-i}\right)$. By $(\mathbf{i}),-\sum_{l \in N}\left(\sigma_{l}-1\right) c_{l} \geq-\sum_{l \in N}\left(\tilde{\sigma}_{l}-1\right) c_{l}$. Thus, $-\left(\sigma_{i}-1\right) c_{i}-\sum_{l \in N \backslash\{i\}}\left(\sigma_{l}-1\right) c_{l}+\bar{h}_{i}\left(c_{-i}\right) \geq-\left(\tilde{\sigma}_{i}-1\right) c_{i}-\sum_{l \in N \backslash\{i\}}\left(\tilde{\sigma}_{l}-\right.$ 1) $c_{l}+g_{i}\left(c_{i}^{\prime}, c_{-i}\right)$. By (ii) and as $\tilde{t}_{i}=-\sum_{l \in N}\left(\tilde{\sigma}_{l}-1\right) c_{l}+g_{i}\left(c_{i}^{\prime}, c_{-i}\right)$, we have $u_{i}\left(\sigma_{i}, t_{i}\right) \geq u_{i}\left(\tilde{\sigma}_{i}, \tilde{t}_{i}\right)$. Thus, $u_{i}\left(\sigma_{i}, t_{i}\right) \geq \max u_{i}\left(\varphi\left(c_{i}^{\prime}, c_{-i}\right)\right)$.

By (iii) and (iv), $\varphi(c) R_{i}\left(c_{i}\right) \varphi\left(c_{i}^{\prime}, c_{-i}\right)$.

Part 2: If $\varphi$ satisfies Pareto-efficiency of queues and strategy-proofness, then it is a Groves rule.

Assume that $\varphi$ satisfies Pareto-efficiency of queues and strategy-proofness. By Pareto-efficiency of queues, for each $c \in \mathbb{R}_{++}^{N}$, if $(\sigma, t) \in \varphi(c)$, then $\sigma \in \bar{\Sigma}^{*}(c)$. Thus, there is $d \in D$ such that for each $c \in \mathbb{R}_{++}^{N}$, we have $d(c) \equiv\{\sigma \in \bar{\Sigma}(N) \mid$ there is $t \in \mathbb{R}$ such that $(\sigma, t) \in \varphi(c)\}$. In Claims 1 and 2, we prove that Pareto-efficiency of queues and strategy-proofness imply that there is $\{\underline{h}, \bar{h}\} \subset H$ such that for each $i \in N$,

- if $(\sigma, t) \in \arg \min u_{i}(\varphi(c))$, then $t_{i}=-\sum_{l \in N \backslash\{i\}}\left(\sigma_{l}-1\right) c_{l}+\underline{h}_{i}\left(c_{-i}\right)$;

- if $(\sigma, t) \in \arg \max u_{i}(\varphi(c))$, then $t_{i}=-\sum_{l \in N \backslash\{i\}}\left(\sigma_{l}-1\right) c_{l}+\bar{h}_{i}\left(c_{-i}\right)$.

Claim 1: There is $\bar{h} \in H$ such that for each $c \in \mathbb{R}_{++}^{N}$ and each $i \in N$, if $(\sigma, t) \in \arg \max u_{i}(\varphi(c))$, then $t_{i}=-\sum_{l \in N \backslash\{i\}}\left(\sigma_{l}-1\right) c_{l}+\bar{h}_{i}\left(c_{-i}\right)$.

Let $\left(\bar{g}_{i}: \mathbb{R}_{++}^{N} \rightarrow \mathbb{R}\right)_{i \in N}$ be a list of real-valued functions such that (i) for each $c \in \mathbb{R}_{++}^{N}$ and each $i \in N$, if $(\sigma, t) \in \arg \max u_{i}(\varphi(c))$, then $t_{i}=-\sum_{l \in N \backslash\{i\}}\left(\sigma_{l}-1\right) c_{l}+\bar{g}_{i}(c)$. By contradiction, assume that (ii) for $c \in \mathbb{R}_{++}^{N}$, $i \in N$, and $c_{i}^{\prime} \in \mathbb{R}$, we have $\Delta \equiv \bar{g}_{i}(c)-\bar{g}_{i}\left(c_{i}^{\prime}, c_{-i}\right)>0$. (The symmetric case is immediate.) Let $(\sigma, t) \in \arg \max u_{i}(\varphi(c))$ and $\left(\sigma^{\prime}, t^{\prime}\right) \in \arg \max u_{i}^{\prime}\left(\varphi\left(c_{i}^{\prime}, c_{-i}\right)\right)$.

By strategy-proofness, $u_{i}\left(\sigma_{i}, t_{i}\right) \geq \max u_{i}\left(\varphi\left(c_{i}^{\prime}, c_{-i}\right)\right)$ and $\max u_{i}^{\prime}(\varphi(c)) \leq$ $u_{i}^{\prime}\left(\sigma_{i}^{\prime}, t_{i}^{\prime}\right)$. By assumption, $\max u_{i}\left(\varphi\left(c_{i}^{\prime}, c_{-i}\right)\right) \geq u_{i}\left(\sigma_{i}^{\prime}, t_{i}^{\prime}\right)$ and $u_{i}^{\prime}\left(\sigma_{i}, t_{i}\right) \leq$ 
$\max u_{i}^{\prime}(\varphi(c))$. Thus, $u_{i}\left(\sigma_{i}, t_{i}\right) \geq u_{i}\left(\sigma_{i}^{\prime}, t_{i}^{\prime}\right)$ and $u_{i}^{\prime}\left(\sigma_{i}, t_{i}\right) \leq u_{i}^{\prime}\left(\sigma_{i}^{\prime}, t_{i}^{\prime}\right)$. By $(\mathbf{i})$, $-\left(\sigma_{i}-1\right) c_{i}-\sum_{l \in N \backslash\{i\}}\left(\sigma_{l}-1\right) c_{l}+\bar{g}_{i}(c) \geq-\left(\sigma_{i}^{\prime}-1\right) c_{i}-\sum_{l \in N \backslash\{i\}}\left(\sigma_{l}^{\prime}-1\right) c_{l}+$ $\bar{g}_{i}\left(c_{i}^{\prime}, c_{-i}\right)$ and $-\left(\sigma_{i}-1\right) c_{i}^{\prime}-\sum_{l \in N \backslash\{i\}}\left(\sigma_{l}-1\right) c_{l}+\bar{g}_{i}(c) \leq-\left(\sigma_{i}^{\prime}-1\right) c_{i}^{\prime}-\sum_{l \in N \backslash\{i\}}\left(\sigma_{l}^{\prime}-\right.$ 1) $c_{l}+\bar{g}_{i}\left(c_{i}^{\prime}, c_{-i}\right)$. Thus,

(iii) $\left(\sigma_{i}-\sigma_{i}^{\prime}\right) c_{i}^{\prime}+\sum_{l \in N \backslash\{i\}}\left(\sigma_{l}-\sigma_{l}^{\prime}\right) c_{l} \geq \Delta \geq\left(\sigma_{i}-\sigma_{i}^{\prime}\right) c_{i}+\sum_{l \in N \backslash\{i\}}\left(\sigma_{l}-\sigma_{l}^{\prime}\right) c_{l}$.

By Pareto-efficiency of queues, for each $S \subseteq N$, if for each $\left\{k, k^{\prime}\right\} \subset S$ with $k \neq k^{\prime}$, we have $c_{k}=c_{k^{\prime}}$ and there is no $k^{\prime \prime} \in N \backslash S$ such that $k^{\prime \prime} \in B_{k k^{\prime}}(\sigma) \cup$ $B_{k k^{\prime}}\left(\sigma^{\prime}\right)$, then $-\sum_{l \in S}\left(\sigma_{l}-1\right) c_{l}=-\sum_{l \in S}\left(\sigma_{l}^{\prime}-1\right) c_{l}$. Also, there is $j \in N$ such that $\sigma_{j}=\sigma_{i}^{\prime}$. Let sign $: \mathbb{R} \rightarrow\{-1,0,1\}$ be such that for each $a \in \mathbb{R}$, $\operatorname{sign}(a)=-1$ if and only if $a<0, \operatorname{sign}(a)=0$ if and only if $a=0$, and $\operatorname{sign}(a)=1$ if and only if $a>0$. Then,

$$
\text { (iv) } \sum_{l \in N \backslash\{i\}}\left(\sigma_{l}-\sigma_{l}^{\prime}\right) c_{l}=-\operatorname{sign}\left(\sigma_{i}-\sigma_{i}^{\prime}\right)\left(\sum_{l \in B_{i j}(\sigma)} c_{l}+c_{j}\right) \text {. }
$$

Assume $c_{i}^{\prime}>c_{i}$. (The symmetric case is immediate.) By Pareto-efficiency of queues, $\sigma_{i}-\sigma_{i}^{\prime} \geq 0$ and $c_{j} \geq c_{i}$. Distinguish three cases.

Case 1: $\left(\sigma_{i}-\sigma_{i}^{\prime}\right)=0$. By (iii) and (iv), $\Delta=0$, contradicting (ii).

Case 2: $\left(\sigma_{i}-\sigma_{i}^{\prime}\right)=1$. By (ii), (iii), (iv), and Pareto-efficiency of queues, (v) $c_{i}^{\prime}-c_{j} \geq \Delta>0 \geq c_{i}-c_{j}$. Let $c_{i}^{\prime \prime} \in \mathbb{R}_{++}$be such that (vi) $\Delta>c_{i}^{\prime \prime}-$ $c_{j}>0$. Let $\left(\sigma^{\prime \prime}, t^{\prime \prime}\right) \in \arg \max u_{i}^{\prime \prime}\left(\varphi\left(c_{i}^{\prime \prime}, c_{-i}\right)\right)$. By (v) and (vi), $c_{i}^{\prime}>c_{i}^{\prime \prime}>$ $c_{j}$. By Pareto-efficiency of queues, $\sigma_{i}^{\prime \prime}=\sigma_{i}^{\prime}$. Thus, (vii) $\sigma_{i}-\sigma_{i}^{\prime \prime}=1$ and by Case 1's logic, ${ }^{10} \bar{g}_{i}\left(c_{i}^{\prime \prime}, c_{-i}\right)=\bar{g}_{i}\left(c_{i}^{\prime}, c_{-i}\right)$. Together, (vi) and (vii) imply $\bar{g}_{i}(c)-\bar{g}_{i}\left(c_{i}^{\prime \prime}, c_{-i}\right)>\left(\sigma_{i}-\sigma_{i}^{\prime \prime}\right) c_{i}^{\prime \prime}-\operatorname{sign}\left(\sigma_{i}-\sigma_{i}^{\prime \prime}\right)\left(\sum_{l \in B_{i j}(\sigma)} c_{l}+c_{j}\right)$. Thus, $-\left(\sigma_{i}-\right.$ $1) c_{i}^{\prime \prime}-\sum_{l \in N \backslash\{i\}}\left(\sigma_{l}-1\right) c_{l}+\bar{g}_{i}(c)>-\left(\sigma_{i}^{\prime \prime}-1\right) c_{i}^{\prime \prime}-\sum_{l \in N \backslash\{i\}}\left(\sigma_{l}^{\prime \prime}-1\right) c_{l}+\bar{g}_{i}\left(c_{i}^{\prime \prime}, c_{-i}\right)$. By $(\mathbf{i}), u_{i}^{\prime \prime}\left(\sigma_{i}, t_{i}\right)>u_{i}^{\prime \prime}\left(\sigma_{i}^{\prime \prime}, t_{i}^{\prime \prime}\right)$. By assumption, $\max u_{i}^{\prime \prime}(\varphi(c)) \geq u_{i}^{\prime \prime}\left(\sigma_{i}, t_{i}\right)$. Thus, $\max u_{i}^{\prime \prime}(\varphi(c))>u_{i}^{\prime \prime}\left(\sigma_{i}^{\prime \prime}, t_{i}^{\prime \prime}\right)$, contradicting strategy-proofness.

Case 3: $\left(\sigma_{i}-\sigma_{i}^{\prime}\right)>1$. Let $\delta \in \mathbb{N}$ be such that $\sigma_{i}-\sigma_{i}^{\prime}=\delta$. For each $s \in$ $\{1,2, \ldots, \delta-1\}$, let $c_{i}^{s} \in \mathbb{R}_{++}$and $\left(\sigma^{s}, t^{s}\right) \in \arg \max u_{i}^{s}\left(\varphi\left(c_{i}^{s}, c_{-i}\right)\right)$ be such that $\sigma_{i}^{s}=\sigma_{i}^{\prime}+s$. By Case 2's logic, ${ }^{11} \bar{g}_{i}\left(c_{i}^{1}, c_{-i}\right)=\bar{g}_{i}\left(c_{i}^{\prime}, c_{-i}\right), \bar{g}_{i}\left(c_{i}^{2}, c_{-i}\right)=$

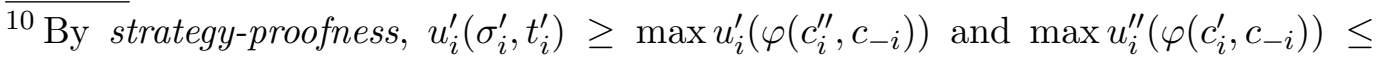
$u_{i}^{\prime \prime}\left(\sigma_{i}^{\prime \prime}, t_{i}^{\prime \prime}\right)$. By assumption, $\max u_{i}^{\prime}\left(\varphi\left(c_{i}^{\prime \prime}, c_{-i}\right)\right) \geq u_{i}^{\prime}\left(\sigma_{i}^{\prime \prime}, t_{i}^{\prime \prime}\right)$ and $u_{i}^{\prime \prime}\left(\sigma_{i}^{\prime}, t_{i}^{\prime}\right) \leq$ $\max u_{i}^{\prime \prime}\left(\varphi\left(c_{i}^{\prime}, c_{-i}\right)\right)$. Thus, $u_{i}^{\prime}\left(\sigma_{i}^{\prime}, t_{i}^{\prime}\right) \geq u_{i}^{\prime}\left(\sigma_{i}^{\prime \prime}, t_{i}^{\prime \prime}\right)$ and $u_{i}^{\prime \prime}\left(\sigma_{i}^{\prime}, t_{i}^{\prime}\right) \leq u_{i}^{\prime \prime}\left(\sigma_{i}^{\prime \prime}, t_{i}^{\prime \prime}\right)$.

${ }^{11}$ By strategy-proofness, $u_{i}^{1}\left(\sigma_{i}^{1}, t_{i}^{1}\right) \geq \max u_{i}^{1}\left(\varphi\left(c_{i}^{\prime}, c_{-i}\right)\right)$ and $\max u_{i}^{\prime}\left(\varphi\left(c_{i}^{1}, c_{-i}\right)\right) \leq$ $u_{i}^{\prime}\left(\sigma_{i}^{\prime}, t_{i}^{\prime}\right)$; for each $s \in\{2, \ldots, \delta-1\}$, we have $u_{i}^{s}\left(\sigma_{i}^{s}, t_{i}^{s}\right) \geq \max u_{i}^{s}\left(\varphi\left(c_{i}^{s-1}, c_{-i}\right)\right)$ and $\max u_{i}^{s-1}\left(\varphi\left(c_{i}^{s}, c_{-i}\right)\right) \leq u_{i}^{s-1}\left(\sigma_{i}^{s-1}, t_{i}^{s-1}\right) ; \ldots ;$ and $u_{i}\left(\sigma_{i}, t_{i}\right) \geq \max u_{i}\left(\varphi\left(c_{i}^{\delta-1}, c_{-i}\right)\right)$ and $\max u_{i}^{\delta-1}(\varphi(c)) \leq u_{i}^{\delta-1}\left(\sigma_{i}^{\delta-1}, t_{i}^{\delta-1}\right)$. By assumption, $\max u_{i}^{1}\left(\varphi\left(c_{i}^{\prime}, c_{-i}\right)\right) \geq$ $u_{i}^{1}\left(\sigma_{i}^{\prime}, t_{i}^{\prime}\right)$ and $u_{i}^{\prime}\left(\sigma_{i}^{1}, t_{i}^{1}\right) \leq \max u_{i}^{\prime}\left(\varphi\left(c_{i}^{1}, c_{-i}\right)\right)$; for each $s \in\{2, \ldots, \delta-1\}$, we have $\max u_{i}^{s}\left(\varphi\left(c_{i}^{s-1}, c_{-i}\right)\right) \geq u_{i}^{s}\left(\sigma_{i}^{s-1}, t_{i}^{s-1}\right)$ and $u_{i}^{s-1}\left(\sigma_{i}^{s}, t_{i}^{s}\right) \leq \max _{i}^{s-1}\left(\varphi\left(c_{i}^{s}, c_{-i}\right)\right) ; \ldots$; and $\max u_{i}\left(\varphi\left(c_{i}^{\delta-1}, c_{-i}\right)\right) \geq u_{i}\left(\sigma_{i}^{\delta-1}, t_{i}^{\delta-1}\right)$ and $u_{i}^{\delta-1}\left(\sigma_{i}, t_{i}\right) \leq \max u_{i}^{\delta-1}(\varphi(c))$. Thus, $u_{i}^{1}\left(\sigma_{i}^{1}, t_{i}^{1}\right) \geq u_{i}^{1}\left(\sigma_{i}^{\prime}, t_{i}^{\prime}\right)$ and $u_{i}^{\prime}\left(\sigma_{i}^{1}, t_{i}^{1}\right) \leq u_{i}^{\prime}\left(\sigma_{i}^{\prime}, t_{i}^{\prime}\right)$; for each $s \in\{2, \ldots, \delta-1\}$, we have $u_{i}^{s}\left(\sigma_{i}^{s}, t_{i}^{s}\right) \geq u_{i}^{s}\left(\sigma_{i}^{s-1}, t_{i}^{s-1}\right)$ and $u_{i}^{s-1}\left(\sigma_{i}^{s}, t_{i}^{s}\right) \leq u_{i}^{s-1}\left(\sigma_{i}^{s-1}, t_{i}^{s-1}\right) ; \ldots ;$ and $u_{i}\left(\sigma_{i}, t_{i}\right) \geq u_{i}\left(\sigma_{i}^{\delta-1}, t_{i}^{\delta-1}\right)$ and $u_{i}^{\delta-1}\left(\sigma_{i}, t_{i}\right) \leq u_{i}^{\delta-1}\left(\sigma_{i}^{\delta-1}, t_{i}^{\delta-1}\right)$.
} 
$\bar{g}_{i}\left(c_{i}^{1}, c_{-i}\right), \ldots, \bar{g}_{i}(c)=\bar{g}_{i}\left(c_{i}^{\delta-1}, c_{-i}\right)$. Thus, $\bar{g}_{i}(c)=\bar{g}_{i}\left(c_{i}^{\prime}, c_{-i}\right)$, contradicting (ii).

Claim 2: There is $\underline{h} \in H$ such that for each $c \in \mathbb{R}_{++}^{N}$ and each $i \in N$, if $(\sigma, t) \in \arg \min u_{i}(\varphi(c))$, then $t_{i}=-\sum_{l \in N \backslash\{i\}}\left(\sigma_{l}-1\right) c_{l}+\underline{h}_{i}\left(c_{-i}\right)$.

Let $\left(\underline{g}_{i}: \mathbb{R}_{++}^{N} \rightarrow \mathbb{R}\right)_{i \in N}$ be a list of real-valued functions such that for each $c \in \mathbb{R}_{++}^{N}$ and each $i \in N$, if $(\sigma, t) \in \arg \min u_{i}(\varphi(c))$, then $t_{i}=-\sum_{l \in N \backslash\{i\}}\left(\sigma_{l}-\right.$ $1) c_{l}+\underline{g}_{i}(c)$. By contradiction, assume that for $c \in \mathbb{R}_{++}^{N}, i \in N$, and $c_{i}^{\prime} \in \mathbb{R}$, we have $\underline{g}_{i}(c)-\underline{g}_{i}\left(c_{i}^{\prime}, c_{-i}\right) \neq 0$. Let $(\sigma, t) \in \arg \min u_{i}(\varphi(c))$ and $\left(\sigma^{\prime}, t^{\prime}\right) \in$ $\arg \min u_{i}^{\prime}\left(\varphi\left(c_{i}^{\prime}, c_{-i}\right)\right)$. Then, the following holds.

(i) If $u_{i}\left(\sigma_{i}, t_{i}\right) \geq u_{i}\left(\sigma_{i}^{\prime}, t_{i}^{\prime}\right)$ and $u_{i}^{\prime}\left(\sigma_{i}, t_{i}\right)>u_{i}^{\prime}\left(\sigma_{i}^{\prime}, t_{i}^{\prime}\right)$, or $u_{i}\left(\sigma_{i}, t_{i}\right)<u_{i}\left(\sigma_{i}^{\prime}, t_{i}^{\prime}\right)$ and $u_{i}^{\prime}\left(\sigma_{i}, t_{i}\right) \leq u_{i}^{\prime}\left(\sigma_{i}^{\prime}, t_{i}^{\prime}\right)$, then for $c_{i}^{\prime \prime}, c_{i}^{\prime \prime \prime} \in \mathbb{R}_{++}$and sufficiently small $\epsilon, \epsilon^{\prime} \in \mathbb{R}$ such that $c_{i}^{\prime \prime}=c_{i}+\epsilon$ and $c_{i}^{\prime \prime \prime}=c_{i}^{\prime}+\epsilon^{\prime}$ and for each $\left(\sigma^{\prime \prime}, t^{\prime \prime}\right) \in \arg \min u_{i}^{\prime \prime}\left(\varphi\left(c_{i}^{\prime \prime}, c_{-i}\right)\right)$ and $\left(\sigma^{\prime \prime \prime}, t^{\prime \prime \prime}\right) \in \arg \min u_{i}^{\prime \prime \prime}\left(\varphi\left(c_{i}^{\prime \prime \prime}, c_{-i}\right)\right)$, we have $u_{i}^{\prime \prime}\left(\sigma_{i}^{\prime \prime}, t_{i}^{\prime \prime}\right) \geq u_{i}^{\prime \prime}\left(\sigma_{i}^{\prime \prime \prime}, t_{i}^{\prime \prime \prime}\right)$ and $u_{i}^{\prime \prime}\left(\sigma_{i}^{\prime \prime}, t_{i}^{\prime \prime}\right) \leq u_{i}^{\prime \prime}\left(\sigma_{i}^{\prime \prime \prime}, t_{i}^{\prime \prime \prime}\right)$. Indeed, assume $u_{i}\left(\sigma_{i}, t_{i}\right) \geq u_{i}\left(\sigma_{i}^{\prime}, t_{i}^{\prime}\right)$ and $u_{i}^{\prime}\left(\sigma_{i}, t_{i}\right)>u_{i}^{\prime}\left(\sigma_{i}^{\prime}, t_{i}^{\prime}\right)$, or $u_{i}\left(\sigma_{i}, t_{i}\right)<$ $u_{i}\left(\sigma_{i}^{\prime}, t_{i}^{\prime}\right)$ and $u_{i}^{\prime}\left(\sigma_{i}, t_{i}\right) \leq u_{i}^{\prime}\left(\sigma_{i}^{\prime}, t_{i}^{\prime}\right)$. Let $c_{i}^{\prime \prime}, c_{i}^{\prime \prime \prime} \in \mathbb{R}_{++}$and sufficiently small $\epsilon, \epsilon^{\prime} \in \mathbb{R}$ be such that $c_{i}^{\prime \prime}=c_{i}+\epsilon$ and $c_{i}^{\prime \prime \prime}=c_{i}^{\prime}+\epsilon^{\prime}$. Let $\left(\sigma^{\prime \prime}, t^{\prime \prime}\right) \in$ $\arg \min u_{i}^{\prime \prime}\left(\varphi\left(c_{i}^{\prime \prime}, c_{-i}\right)\right)$ and $\left(\sigma^{\prime \prime \prime}, t^{\prime \prime \prime}\right) \in \arg \min u_{i}^{\prime \prime \prime}\left(\varphi\left(c_{i}^{\prime \prime \prime}, c_{-i}\right)\right)$. By strategyproofness, $u_{i}^{\prime \prime}\left(\sigma_{i}^{\prime \prime}, t_{i}^{\prime \prime}\right) \geq \min u_{i}^{\prime \prime}\left(\varphi\left(c_{i}^{\prime \prime \prime}, c_{-i}\right)\right)$ and $\min u_{i}^{\prime \prime \prime}\left(\varphi\left(c_{i}^{\prime \prime}, c_{-i}\right)\right) \leq$ $u_{i}^{\prime \prime \prime}\left(\sigma_{i}^{\prime \prime \prime}, t_{i}^{\prime \prime \prime}\right)$. By Pareto-efficiency of queues, for each $(\tilde{\sigma}, \tilde{t}),\left(\tilde{\sigma}^{\prime}, \tilde{t}^{\prime}\right) \in$ $\varphi\left(c_{i}^{\prime \prime}, c_{-i}\right)$, we have $\tilde{\sigma}_{i}=\tilde{\sigma}_{i}^{\prime}$. Also, for each $(\tilde{\sigma}, \tilde{t}),\left(\tilde{\sigma}^{\prime}, \tilde{t}^{\prime}\right) \in \varphi\left(c_{i}^{\prime \prime \prime}, c_{-i}\right)$, we have $\tilde{\sigma}_{i}=\tilde{\sigma}_{i}^{\prime}$. Thus, $\arg \min u_{i}^{\prime \prime}\left(\varphi\left(c_{i}^{\prime \prime \prime}, c_{-i}\right)\right)=\arg \min u_{i}^{\prime \prime \prime}\left(\varphi\left(c_{i}^{\prime \prime \prime}, c_{-i}\right)\right)$ and $\arg \min u_{i}^{\prime \prime \prime}\left(\varphi\left(c_{i}^{\prime \prime}, c_{-i}\right)\right)=\arg \min u_{i}^{\prime \prime}\left(\varphi\left(c_{i}^{\prime \prime}, c_{-i}\right)\right)$. Thus, $u_{i}^{\prime \prime}\left(\sigma_{i}^{\prime \prime}, t_{i}^{\prime \prime}\right) \geq$ $u_{i}^{\prime \prime}\left(\sigma_{i}^{\prime \prime \prime}, t_{i}^{\prime \prime \prime}\right)$ and $u_{i}^{\prime \prime \prime}\left(\sigma_{i}^{\prime \prime}, t_{i}^{\prime \prime}\right) \leq u_{i}^{\prime \prime \prime}\left(\sigma_{i}^{\prime \prime \prime}, t_{i}^{\prime \prime \prime}\right)$.

(ii) For each $c_{i}^{\prime \prime}, c_{i}^{\prime \prime \prime} \in \mathbb{R}_{++}$, if for sufficiently small $\epsilon, \epsilon^{\prime} \in \mathbb{R}$, we have $c_{i}^{\prime \prime}=c_{i}+\epsilon$ and $c_{i}^{\prime \prime \prime}=c_{i}^{\prime}+\epsilon^{\prime}$, then $\underline{g}_{i}(c)=\underline{g}_{i}\left(c_{i}^{\prime \prime}, c_{-i}\right)$ and $\underline{g}_{i}\left(c_{i}^{\prime}, c_{-i}\right)=$ $\underline{g}_{i}\left(c_{i}^{\prime \prime \prime}, c_{-i}\right)$. Indeed, let $c_{i}^{\prime \prime} \in \mathbb{R}_{++} \bar{b}$ e such that for sufficiently small $\underline{\epsilon}_{i} \in \mathbb{R}$, we have $c_{i}^{\prime \prime}=c_{i}+\epsilon$. By contradiction, assume $\underline{g}_{i}(c)-$ $\underline{g}_{i}\left(c_{i}^{\prime \prime}, c_{-i}\right) \neq 0$. (The other case is immediate.) Let $(\sigma, t) \in \arg \min \underline{u}_{i}(\varphi(c))$ and $\left(\sigma^{\prime \prime}, t^{\prime \prime}\right) \in \arg \min u_{i}^{\prime \prime}\left(\varphi\left(c_{i}^{\prime \prime}, c_{-i}\right)\right)$. By strategy-proofness, $u_{i}\left(\sigma_{i}, t_{i}\right) \geq$ $\min u_{i}\left(\varphi\left(c_{i}^{\prime \prime}, c_{-i}\right)\right)$ and $\min u_{i}^{\prime \prime}(\varphi(c)) \leq u_{i}^{\prime \prime}\left(\sigma_{i}^{\prime \prime}, t_{i}^{\prime \prime}\right)$. As $c_{i}^{\prime \prime}=c_{i}+\epsilon$, we have $\arg \min u_{i}\left(\varphi\left(c_{i}^{\prime \prime}, c_{-i}\right)\right)=\arg \min u_{i}^{\prime \prime}\left(\varphi\left(c_{i}^{\prime \prime}, c_{-i}\right)\right)$ and $\arg \min u_{i}^{\prime \prime}(\varphi(c))=$ $\arg \min u_{i}(\varphi(c))$. Thus, $u_{i}\left(\sigma_{i}, t_{i}\right) \geq u_{i}\left(\sigma_{i}^{\prime \prime}, t_{i}^{\prime \prime}\right)$ and $u_{i}^{\prime}\left(\sigma_{i}, t_{i}\right) \leq u_{i}^{\prime \prime}\left(\sigma_{i}^{\prime \prime}, t_{i}^{\prime \prime}\right)$. By Claim 1's logic, we obtain a contradiction. ${ }^{12}$

$B y(\mathbf{i})$ and (ii), w.l.o.g. assume $u_{i}\left(\sigma_{i}, t_{i}\right) \geq u_{i}\left(\sigma_{i}^{\prime}, t_{i}^{\prime}\right)$ and $u_{i}^{\prime}\left(\sigma_{i}, t_{i}\right) \leq u_{i}^{\prime}\left(\sigma_{i}^{\prime}, t_{i}^{\prime}\right)$. By Claim 1's logic, we obtain a contradiction. ${ }^{12}$

Nota 1 By Theorem 1, a single-valued rule satisfies Pareto-efficiency of

$\overline{12}$ Claim 2's extended proof, using at this point Claim 1's logic, is available to the reader upon request to us. 
queues and strategy-proofness if and only if it is a single-valued Groves rule. As preferences are convex, this corrolary follows from Holmström's result (1979). Thus, in Theorem 1, we prove that even in the more general case, in which one does not impose single-valuedness, only Groves rules satisfy these axioms. This characterization holds on many other domains.

Indeed, for single-valued rules, the main argument is that for any pair of the privately known parameters, there is a preference reversal on the alternatives selected, one for each parameter. Thus, if the domain is rich enough, there always is another parameter such that the same alternatives are selected, one for this parameter, one for one of the former parameters, and there is no preference reversal (Holmström, 1979). For non-single-valued rules, the existence of such preference reversals is not guaranteed. We prove that in the cases where for some pair of parameters, it is not guaranteed, if the domain is rich enough, there always is another pair of parameters such that the same alternatives are selected, and there is such a preference reversal.

The class of Groves rules is large. We may distinguish subclasses. In particular, a Groves rule associated with a unique $h \in H$ is such that for each $c \in \mathbb{R}_{++}^{N}$, if $(\sigma, t)$ is selected, then for each $i \in N$, we have $t_{i}=-\sum_{l \in N \backslash\{i\}}\left(\sigma_{l}-1\right) c_{l}+h_{i}\left(c_{-i}\right)$.

For instance, a Pivotal rule selects for each problem, Pareto-efficient queues and sets transfers such that each agent pays what she imposes on the others if she is pivotal on the choice of the queue, and nothing otherwise (Clarke, 1971). Each agent is always pivotal on the choice of a Pareto-efficient queue. Indeed, for $\sigma \in \bar{\Sigma}(N)$ and $i \in N$, let $\sigma^{-i} \in \bar{\Sigma}(N \backslash\{i\})$ be such that for each $l \in P_{i}(\sigma)$, we have $\sigma_{l}^{-i}=\sigma_{l}$ and for each $l \in F_{i}(\sigma)$, we have $\sigma_{l}^{-i}=\sigma_{l}-1$. For each $c \in \mathbb{R}_{++}^{N}$, each $\sigma \in \bar{\Sigma}^{*}(c)$, each $S \subseteq N$, the cost that $i$ imposes on $S$ is $\left(\sum_{l \in S}\left(\sigma_{l}-1\right) c_{l}\right)-\left(\sum_{l \in S \backslash\{i\}}\left(\sigma_{l}^{-i}-1\right) c_{l}\right)=\sum_{l \in S \cap F_{i}(\sigma)} c_{l}$. Thus, the cost an agent imposes on the others is always equal to the sum of the costs her followers incur by waiting one more unit of time. Formally, Pivotal rules are Groves rules associated with $h \in H$ such that for each $c \in \mathbb{R}_{++}^{N}$, if $(\sigma, t)$ is selected, then for each $i \in N$, we have $h_{i}\left(c_{-i}\right)=\sum_{l \in N \backslash\{i\}}\left(\sigma_{l}^{-i}-1\right) c_{l}$.

By Theorem 1, a rule satisfies Pareto-efficiency and strategy-proofness if and only if it is a Groves rules and it satisfies balancedness. Yet, in two-agent problems, no Groves rule satisfies balancedness (Suijs, 1996). ${ }^{13}$ Thus, from now on, we focus on problems with more than two agents.

We introduce a new rule. For each problem, it selects all Pareto-efficient queues and sets transfers considering each pair of agents in turn, making each

\footnotetext{
${ }^{13}$ Suijs $(1996)$ proves this impossibility for single-valued rules. One can prove it for any rules using Suijs' result's logic, Theorem 1, and the fact that if the agents unit costs differ, by balancedness, a bundle maximizes one agent's utility if and only if the corresponding bundle minimizes the other's.
} 
agent in the pair pay what a Pivotal rule recommends for the reduced problem consisting of these two agents, and distributing the sum of these two payments equally among the others. For each problem and each selected Pareto-efficient queue, each agent pays the cost she imposes on each pair of agents she could be in, and she receives $(1 /(n-2))$ th of the cost each other agent imposes on each pair of agents this agent is and she is not. Thus, each agent pays the unit waiting costs of her followers, and she receives $(1 /(n-2))$ th of the unit waiting costs of each other agent's followers, but her. Formally,

The Largest Equally Distributed Pairwise Pivotal (LEDPP) rule, $\varphi^{\mathbf{L}}:$ For each $c \in \mathbb{R}_{++}^{N}$, we have $(\sigma, t) \in \varphi^{L}(c)$ if and only if $\sigma \in \bar{\Sigma}^{*}(c)$ and for each $i \in N$, we have $t_{i}=-\sum_{l \in F_{i}(\sigma)} c_{l}+\frac{1}{(n-2)} \sum_{j \in N \backslash\{i\}} \sum_{l \in F_{j}\left(\sigma^{-i}\right)} c_{l}$.

As there may be several Pareto-efficient queues for a problem, this rule has several subcorrespondences. We refer to these and to the LEDPP rule as Equally Distributed Pairwise Pivotal (EDPP) rules.

We now prove that for each problem and each selected Pareto-efficient queue, we obtain the transfers of the LEDPP rule, or of any other EDPP rule, in three other ways. First, making each agent pay what a Pivotal rule recommends for the problem and giving each agent $(1 /(n-2))$ th of the others' minimum total waiting cost if she was not there. Second, giving each agent $(1 /(n-2))$ th of her predecessors' total waiting cost and making each agent pay $(1 /(n-2)) t h$ of her followers' waiting gain from not being last in the queue (Mitra and Sen, 1998; Mitra, 2001). Third, giving each agent $1 / 2$ of her predecessors' unit waiting cost and making each agent pay $1 / 2$ of her followers' unit waiting cost plus $(1 / 2(n-2))$ th of the difference in the unit waiting costs of each agent, but her and each of this agent's predecessors's, but her (Suijs, 1996).

Theorem 2 Let $\varphi$ be a rule. The following statements are equivalent.

(1) $\varphi$ is an Equally Distributed Pairwise Pivotal rule.

(2) $\varphi$ is a Groves rule associated with $h \in H$ such that for each $c \in \mathbb{R}_{++}^{N}$, if $(\sigma, t) \in \varphi(c)$, then for each $i \in N$, we have $h_{i}\left(c_{-i}\right)=\sum_{l \in N \backslash\{i\}}\left(\sigma_{l}^{-i}-\right.$ 1) $c_{l}+\frac{1}{(n-2)} \sum_{l \in N \backslash\{i\}}\left(\sigma_{l}^{-i}-1\right) c_{l}$.

(3) $\varphi$ is such that for each $c \in \mathbb{R}_{++}^{N}$, if $(\sigma, t) \in \varphi(c)$, then $\sigma \in \bar{\Sigma}^{*}(c)$ and for each $i \in N$, we have $t_{i}=\sum_{l \in P_{i}(\sigma)} \frac{\left(\sigma_{l}-1\right)}{(n-2)} c_{l}-\sum_{l \in F_{i}(\sigma)} \frac{\left(n-\sigma_{l}\right)}{(n-2)} c_{l}$.

(4) $\varphi$ is such that for each $c \in \mathbb{R}_{++}^{N}$, if $(\sigma, t) \in \varphi(c)$, then $\sigma \in$ $\bar{\Sigma}^{*}(c)$ and for each $i \in N$, we have $t_{i}=\sum_{l \in P_{i}(\sigma)} \frac{c_{l}}{2}-\sum_{l \in F_{i}(\sigma)} \frac{c_{l}}{2}-$ $\sum_{l \in N \backslash\{i\}} \sum_{k \in P_{l}(\sigma) \backslash\{i\}} \frac{c_{k}-c_{l}}{2(n-2)}$.

Proof. Assume that $\varphi$ is as in Statement 1. Let $c \in \mathbb{R}_{++}^{N},(\sigma, t) \in \varphi(c)$, and $i \in N$. Then,

$t_{i}=-\sum_{l \in F_{i}(\sigma)} c_{l}+\frac{1}{(n-2)} \sum_{j \in N \backslash\{i\}} \sum_{l \in F_{j}\left(\sigma^{-i}\right)} c_{l}$ (1.) 


$$
\begin{aligned}
& =-\sum_{l \in F_{i}(\sigma)} c_{l}+\frac{1}{(n-2)} \sum_{l \in N \backslash\{i\}}\left(\sigma_{l}^{-i}-1\right) c_{l} \\
& =-\sum_{l \in N \backslash\{i\}}\left(\sigma_{l}-1\right) c_{l}+\sum_{l \in N \backslash\{i\}}\left(\sigma_{l}^{-i}-1\right) c_{l}+\frac{1}{(n-2)} \sum_{l \in N \backslash\{i\}}\left(\sigma_{l}^{-i}-1\right) c_{l} \\
& =-\sum_{l \in F_{i} \sigma} c_{l}+\frac{1}{n-2} \sum_{l \in P_{i}(\sigma)}\left(\sigma_{l}-1\right) c_{l}+\frac{1}{(n-2)} \sum_{l \in F_{i}(\sigma)}\left(\sigma_{l}-2\right) c_{l} \\
& =\sum_{l \in P_{i}(\sigma)} \frac{\left(\sigma_{l}-1\right)}{(n-2)} c_{l}+\sum_{l \in F_{i}(\sigma)} \frac{\left(\sigma_{l}-2\right)-(n-2)}{(n-2)} c_{l} \\
& =\sum_{l \in P_{i}(\sigma)} \frac{\left(\sigma_{l}-1\right)}{(n-2)} c_{l}-\sum_{l \in F_{i}(\sigma)} \frac{\left(n-\sigma_{l}\right)}{(n-2)} c_{l} \quad \text { (3.) } \\
& =\sum_{l \in P_{i}(\sigma)} \frac{c_{l}}{2}-\sum_{l \in F_{i}(\sigma)} \frac{c_{l}}{2}-\sum_{l \in N \backslash\{i\}} \frac{\left(n-2 \sigma_{l}\right) c_{l}}{2(n-2)} \\
& =\sum_{l \in P_{i}(\sigma)} \frac{c_{l}}{2}-\sum_{l \in F_{i}(\sigma)} \frac{c_{l}}{2}-\left[\sum_{l \in N \backslash\{i\}} \frac{\left(n-\sigma_{l}-1\right) c_{l}}{2(n-2)}-\sum_{l \in N \backslash\{i\}} \frac{\left(\sigma_{l}-1\right) c_{l}}{2(n-2)}\right] \\
& =\sum_{l \in P_{i}(\sigma)} \frac{c_{l}}{2}-\sum_{l \in F_{i}(\sigma)} \frac{c_{l}}{2}-\sum_{l \in N \backslash\{i\}} \sum_{k \in P_{l}(\sigma) \backslash\{i\}} \frac{c_{k}-c_{l}}{2(n-2)} . \quad \text { (4.) }
\end{aligned}
$$

We now come to our central result. We prove that only EDPP rules satisfy Pareto-efficiency, equal treatment of equals in welfare, and strategy-proofness. They satisfy no-envy. Only the LEDPP rule satisfies Pareto-efficiency, symmetry, and strategy-proofness. It satisfies anonymity. Thus, as no-envy implies equal treatment of equals in welfare and anonymity implies symmetry, we prove that only the LEDPP rule satisfies the axioms we impose.

This central result holds for variants of the incentive compatibility property we impose. First, in Statement 2's proof, we prove that any EDPP rule is such that each agent always finds any bundle she may receive when revealing her unit waiting cost at least as desirable as any bundle she may receive when misrepresenting it. Second, in Statement 1's proof, we prove that if a rule satisfies Pareto-efficiency, equal treatment of equals in welfare, and is such that each agent always finds the worst bundle she may receive when revealing her unit waiting cost at least desirable as the worst bundle she may receive when misrepresenting it, it is an EDPP rule. The same holds, considering best bundles only. Thus, our result holds for stronger, as well as weaker incentive criteria, embodying extreme uncertainty aversions.

Theorem 3 Let $\varphi$ be a rule.

(1) If $\varphi$ satisfies Pareto-efficiency, equal treatment of equals in welfare, and strategy-proofness, then it is a subcorrespondence of the Largest Equally Distributed Pairwise Pivotal rule.

(2) If $\varphi$ is a subcorrespondence of the Largest Equally Distributed Pairwise Pivotal rule, then it satisfies Pareto-efficiency, no-envy, and strategyproofness.

(3) If $\varphi$ satisfies Pareto-efficiency, symmetry, and strategy-proofness, then it is the Largest Equally Distributed Pairwise Pivotal rule.

(4) If $\varphi$ is the Largest Equally Distributed Pairwise Pivotal rule, then it satisfies Pareto-efficiency, anonymity, and strategy-proofness.

\section{Proof.}


Statement 1: Assume that $\varphi$ satisfies the axioms of Theorem 3.1. Let $c \in \mathbb{R}_{++}^{N}$. By Pareto-efficiency, for each $(\sigma, t) \in \varphi(c)$, we have $\sigma \in \bar{\Sigma}^{*}(c)$. By Theorem 1, Pareto-efficiency and strategy-proofness imply that there is $\{\underline{h}, \bar{h}\} \subset H$ such that for each $i \in N$,

- if $(\sigma, t) \in \arg \min u_{i}(\varphi(c))$, then $t_{i}=-\sum_{l \in N \backslash\{i\}}\left(\sigma_{l}-1\right) c_{l}+\underline{h}_{i}\left(c_{-i}\right)$;

- if $(\sigma, t) \in \arg \max u_{i}(\varphi(c))$, then $t_{i}=-\sum_{l \in N \backslash\{i\}}\left(\sigma_{l}-1\right) c_{l}+\bar{h}_{i}\left(c_{-i}\right)$.

Let $\left\{\left(\underline{\gamma}_{i}\right)_{i \in N},\left(\bar{\gamma}_{i}\right)_{i \in N}\right\} \subset H$ be such that for each $i \in N$,

- if $(\sigma, t) \in \arg \min u_{i}(\varphi(c))$, then $\underline{h}_{i}\left(c_{-i}\right)=\sum_{l \in N \backslash\{i\}}\left(\sigma_{l}^{-i}-1\right) c_{l}+\underline{\gamma}_{i}\left(c_{-i}\right)$;

- if $(\sigma, t) \in \arg \max u_{i}(\varphi(c))$, then $\bar{h}_{i}\left(c_{-i}\right)=\sum_{l \in N \backslash\{i\}}\left(\sigma_{l}^{-i}-1\right) c_{l}+\bar{\gamma}_{i}\left(c_{-i}\right)$.

W.l.o.g. assume $N=\{1, \ldots, n\}$ and $c_{1} \geq \ldots \geq c_{n}$. For $S \subseteq N$, let $c_{S} \equiv\left(c_{l}\right)_{l \in S}$ be the list of the unit waiting costs of the members of $S$ and $c_{n}^{S} \equiv\left(c_{n}\right)_{l \in S}$ be the list of the unit waiting costs of the members of $S$ when for each $l \in S$, we have $c_{l}=c_{n}$. Let $\sigma^{S} \in \bar{\Sigma}^{*}\left(c_{S}\right) \equiv\left\{\left(\sigma_{i}\right)_{i \in S} \in \mathbb{N}^{S} \mid(i)\right.$ for each $\{i, j\} \subset S$, we have $\sigma_{i} \neq \sigma_{j}$ and (ii) for each $\left(\sigma_{i}^{\prime}\right)_{i \in S} \in \mathbb{N}^{S}$ such that for each $\{i, j\} \in S$, we have $\sigma_{i}^{\prime} \neq \sigma_{j}^{\prime}$, we have $\left.\sum_{i \in S}\left(\sigma_{i}^{\prime}-1\right) c_{i} \geq \sum_{i \in S}\left(\sigma_{i}-1\right) c_{i}\right\}$.

For each $\tilde{c} \in\left\{\left(c_{n}, \ldots, c_{n}\right),\left(c_{1}, c_{n}, \ldots, c_{n}\right), \ldots,\left(c_{1}, \ldots, c_{n-1}, c_{n}\right)\right\}$, each $(\tilde{\sigma}, \tilde{t}) \in \varphi(\tilde{c})$, and each $\left(\gamma_{i}\right)_{i \in N} \in H$, if for each $i \in N$, we have $\tilde{t}_{i}=-\sum_{l \in N \backslash\{i\}}\left(\tilde{\sigma}_{l}-1\right) \tilde{c}_{l}+\sum_{l \in N \backslash\{i\}}\left(\tilde{\sigma}_{l}^{-i}-1\right) \tilde{c}_{l}+\gamma_{i}\left(\tilde{c}_{-i}\right)$, the following holds.

Step 0: $\left(c_{n}, \ldots, c_{n}\right) \in \mathbb{R}_{++}^{N}$.

By Pareto-efficiency, $\sum_{i \in N} \gamma_{i}\left(c_{n}^{N \backslash\{i\}}\right)=\frac{n(n-1)}{2} c_{n}$. By equal treatment of equals in welfare, $\gamma_{1}\left(c_{n}^{N \backslash\{1\}}\right)=\ldots=\gamma_{n}\left(c_{n}^{N \backslash\{n\}}\right)$. Thus, for each $i \in N$, we have $\gamma_{i}\left(c_{n}^{N \backslash\{i\}}\right)=\frac{(n-1)}{2} c_{n}$.

Step 1: $\left(c_{1}, c_{n}, \ldots, c_{n}\right) \in \mathbb{R}_{++}^{N}$.

By Pareto-efficiency, $\gamma_{1}\left(c_{n}^{N \backslash\{1\}}\right)+\sum_{i \in N \backslash\{1\}} \gamma_{i}\left(c_{1}, c_{n}^{N \backslash\{1, i\}}\right)=\frac{(n-1) n}{2} c_{n} . B y$ Step 0, $\gamma_{1}\left(c_{n}^{N \backslash\{1\}}\right)=\frac{(n-1)}{2} c_{n}$. By equal treatment of equals in welfare, $\gamma_{2}\left(c_{1}, c_{n}^{N \backslash\{1,2\}}\right)=\ldots=\gamma_{n}\left(c_{1}, c_{n}^{N \backslash\{1, n\}}\right)$. Thus, for each $i \in N \backslash\{1\}$, we have $\gamma_{i}\left(c_{1}, c_{n}^{N \backslash\{1, i\}}\right)=\frac{(n-1)}{2} c_{n}$.

By the same logic, for each $l \neq 1 \in N$ and each $i \in N \backslash\{l\}$, we have $\gamma_{i}\left(c_{l}, c_{n}^{N \backslash\{l, i\}}\right)=\frac{(n-1)}{2} c_{n}$.

Step 2: $\left(c_{1}, c_{2}, c_{n}, \ldots, c_{n}\right) \in \mathbb{R}_{++}^{N}$.

By Pareto-efficiency, $\quad \sum_{i \in\{1,2\}} \gamma_{i}\left(c_{\{1,2\} \backslash\{i\}}, c_{n}^{N \backslash\{1,2\}}\right) \quad+$ $\sum_{i \in N \backslash\{1,2\}} \gamma_{i}\left(c_{\{1,2\}}, c_{n}^{N \backslash\{1,2, i\}}\right)=c_{2}+\frac{(n-2)(n+1)}{2} c_{n}$. By Step 1, for each $i \in\{1,2\}$, we have $\gamma_{i}\left(c_{\{1,2\} \backslash\{i\}}, c_{n}^{N \backslash\{1,2\}}\right)=\frac{(n-1)}{2} c_{n}$. By equal treatment of equals in welfare, $\gamma_{3}\left(c_{\{1,2\}}, c_{n}^{N \backslash\{1,2,3\}}\right)=\ldots=\gamma_{n}\left(c_{\{1,2\}}, c_{n}^{N \backslash\{1,2, n\}}\right)$. Thus, for each $i \in N \backslash\{1,2\}$, we have $\gamma_{i}\left(c_{\{1,2\}}, c_{n}^{N \backslash\{1,2, i\}}\right)=\frac{1}{(n-2)} c_{2}+\frac{(n-3) n}{2(n-2)} c_{n}$.

By the same logic, for each $\left\{l, l^{\prime}\right\} \neq\{1,2\} \subset N$ and each $i \in N \backslash\left\{l, l^{\prime}\right\}$, we have $\gamma_{i}\left(c_{\left\{l, l^{\prime}\right\}}, c_{n}^{N \backslash\left\{l, l^{\prime}, i\right\}}\right)=\sum_{k \in\left\{l, l^{\prime}\right\}} \frac{\left(\sigma_{k}^{\left\{l, l^{\prime}\right\}}-1\right)}{(n-2)} c_{k}+\frac{(n-3) n}{2(n-2)} c_{n}$. 
Step s: $\left(c_{1}, \ldots, c_{s}, c_{n}, \ldots, c_{n}\right) \in \mathbb{R}_{++}^{N}$.

By Pareto-efficiency, $\quad \sum_{i \in\{1, \ldots, s\}} \gamma_{i}\left(c_{\{1, \ldots, s\} \backslash\{i\}}, c_{n}^{N \backslash\{1, \ldots, s\}}\right) \quad+$ $\sum_{i \in N \backslash\{1, \ldots, s\}} \gamma_{i}\left(c_{\{1, \ldots, s\}}, c_{n}^{N \backslash\{1, \ldots, s, i\}}\right)=\sum_{i \in\{1, \ldots, s\}}\left(\sigma_{i}^{\{1, \ldots, s\}}-1\right) c_{i}+\frac{(n-s)(n+s-1)}{2} c_{n}$. By Step $s-1$, for each $i \in\{1, \ldots, s\}$, we have $\gamma_{i}\left(c_{\{1, \ldots, s\} \backslash\{i\}}, c_{n}^{N \backslash\{1, \ldots, s\}}\right)=$ $\sum_{l \in\{1, \ldots, s\} \backslash\{i\}} \frac{\left(\sigma_{l}^{\{1, \ldots, s\} \backslash\{i\}}-1\right)}{(n-2)} c_{l}+\frac{(n-(s-1)-1)(n+(s-1)-2)}{2(n-2)} c_{n}$. By equal treatment of equals in welfare, $\gamma_{s+1}\left(c_{\{1, \ldots, s\}}, c_{n}^{N \backslash\{1, \ldots, s, s+1\}}\right)=\ldots=\gamma_{n}\left(c_{\{1, \ldots, s\}}, c_{n}^{N \backslash\{1, \ldots, s, n\}}\right)$. Thus, for each $i \in N \backslash\{1, \ldots, s\}$, we have $\gamma_{i}\left(c_{\{1, \ldots, s\}}, c_{n}^{N \backslash\{1, \ldots, s, i\}}\right)=$ $\sum_{l \in\{1, \ldots, s\}} \frac{\left(\sigma_{l}^{\{1, \ldots, s\}}-1\right)}{(n-2)} c_{l}+\frac{(n-s-1)(n+s-2)}{2(n-2)} c_{n}$.

By the same logic, for each $S \neq\{1, \ldots, s\} \subset N$ with $|S|=$ s and each $i \in N \backslash S$, we have $\gamma_{i}\left(c_{S}, c_{n}^{N \backslash(S \cup\{i\})}\right)=\sum_{l \in S} \frac{\left(\sigma_{l}^{S}-1\right)}{(n-2)} c_{l}+\frac{(n-s-1)(n+s-2)}{2(n-2)} c_{n}$.

$\cdots$

Step $\mathbf{n}-\mathbf{1}:\left(c_{1}, \ldots, c_{n-1}, c_{n}\right) \in \mathbb{R}_{++}^{N}$.

By Pareto-efficiency, $\sum_{i \in\{1, \ldots, n-1\}} \gamma_{i}\left(c_{\{1, \ldots, n-1\} \backslash\{i\}}, c_{n}\right)+\gamma_{n}\left(c_{\{1, \ldots, n-1\}}\right)=$ $\sum_{i \in\{1, \ldots, n-1\}}\left(\sigma_{i}^{\{1, \ldots, n-1\}}-1\right) c_{i}+(n-1) c_{n}$. By Step $n-2$, (i) for each $i \in\{1, \ldots, n-$ $1\}$, we have $\gamma_{i}\left(c_{\{1, \ldots, n-1\} \backslash\{i\}}, c_{n}\right)=\sum_{l \in\{1, \ldots, n-1\} \backslash\{i\}} \frac{\left(\sigma_{l}^{\{1, \ldots, n-1\} \backslash\{i\}}-1\right)}{(n-2)} c_{l}+c_{n}$. Thus, (ii) $\gamma_{n}\left(c_{\{1, \ldots, n-1\}}\right)=\sum_{l \in\{1, \ldots, n-1\}} \frac{\left(\sigma_{l}^{\{1, \ldots, n-1\}}-1\right)}{(n-2)} c_{l}$. By (i) and (ii), for each $i \in N$, we have $\gamma_{i}\left(c_{-i}\right)=\sum_{l \in N \backslash\{i\}} \frac{\left(\sigma_{l}^{N \backslash\{i\}}-1\right)}{(n-2)} c_{l}=\sum_{l \in N \backslash\{i\}} \frac{\left(\tilde{\sigma}_{l}^{-i}-1\right)}{(n-2)} c_{l}$.

By this step process' logic, for each $i \in N$, if $(\sigma, t) \in \arg \min u_{i}(\varphi(c)) \cup$ $\arg \min u_{i}(\varphi(c))$, then $t_{i}=-\sum_{l \in N \backslash\{i\}}\left(\sigma_{l}-1\right) c_{l}+\sum_{l \in N \backslash\{i\}}\left(\sigma_{l}^{-i}-1\right) c_{l}+$ $\frac{1}{(n-2)} \sum_{l \in N \backslash\{i\}}\left(\sigma_{l}^{-i}-1\right) c_{l}$.

Let $i \in N,(\underline{\sigma}, \underline{t}) \in \arg \min u_{i}(\varphi(c)),(\bar{\sigma}, \bar{t}) \in \arg \max u_{i}(\varphi(c))$, and $(\sigma, t) \in \varphi(c)$. By Pareto-efficiency of queues, $\sum_{l \in N}\left(\underline{\sigma}_{l}-1\right) c_{l}=\sum_{l \in N}\left(\bar{\sigma}_{l}-1\right) c_{l}$ and $\sum_{l \in N \backslash\{i\}}\left(\underline{\sigma}_{l}^{-i}-1\right) c_{l}=\sum_{l \in N \backslash\{i\}}\left(\bar{\sigma}_{l}^{-i}-1\right) c_{l}$. Thus, $u_{i}\left(\underline{\sigma}_{i}, \underline{t}_{i}\right)=u_{i}\left(\bar{\sigma}_{i}, \bar{t}_{i}\right)$. Thus, $t_{i}=-\sum_{l \in N \backslash\{i\}}\left(\sigma_{l}-1\right) c_{l}+\sum_{l \in N \backslash\{i\}}\left(\sigma_{l}^{-i}-1\right) c_{l}+\frac{1}{(n-2)} \sum_{l \in N \backslash\{i\}}\left(\sigma_{l}^{-i}-1\right) c_{l}$. By Theorem 2, $t_{i}=-\sum_{l \in F_{i}(\sigma)} c_{l}+\frac{1}{(n-2)} \sum_{j \in N \backslash\{i\}} \sum_{l \in F_{j}\left(\sigma^{-i}\right)} c_{l} \cdot{ }^{14}$

\section{Statement 2:}

Pareto-efficiency: Assume that for each $c \in \mathbb{R}_{++}^{N}$, we have $\varphi(c) \subseteq \varphi^{L}(c)$. Let

$\overline{{ }^{14} \text { Assume }}(\sigma, t) \notin \arg \min u_{i}(\varphi(c))$. (The "max" case is immediate.) Let $\left(\Delta_{k}\right)_{k \in N} \in$ $\mathbb{R}^{N}$ be such that for each $k \in N$, we have $t_{k}=-\sum_{l \in N \backslash\{k\}}\left(\sigma_{l}-1\right) c_{l}+\sum_{l \in N \backslash\{k\}}\left(\sigma_{l}^{-k}-\right.$ 1) $c_{l}+\frac{1}{(n-2)} \sum_{l \in N \backslash\{k\}}\left(\sigma_{l}^{-k}-1\right) c_{l}+\Delta_{k}$. By Pareto-efficiency of queues, $\sum_{l \in N}\left(\underline{\sigma}_{l}-\right.$ 1) $c_{l}=\sum_{l \in N}\left(\sigma_{l}-1\right) c_{l}$ and $\sum_{l \in N \backslash\{i\}}\left(\underline{\sigma}_{l}^{-i}-1\right) c_{l}=\sum_{l \in N \backslash\{i\}}\left(\sigma_{l}^{-j}-1\right) c_{l}$. Thus, $\Delta_{i}>0$. By balancedness, there is $j \in N$ such that $\Delta_{j}<0$. Let $(\underline{\underline{\sigma}}, \underline{\underline{t}}) \in$ $\arg \min u_{j}(\varphi(c))$. By Pareto-efficiency of queues, $\sum_{l \in N}\left(\underline{\underline{\sigma}}_{l}-1\right) c_{l}=\sum_{l \in N}\left(\sigma_{l}-1\right) c_{l}$ and $\sum_{l \in N \backslash\{j\}}\left(\underline{\underline{\sigma}}_{l}^{-j}-1\right) c_{l}=\sum_{l \in N \backslash\{j\}}\left(\sigma_{l}^{-j}-1\right) c_{l}$. Thus, $u_{j}\left(\underline{\underline{\sigma}}_{j}, \underline{\underline{t}}_{j}\right)>u_{j}\left(\sigma_{j}, t_{j}\right)$, contra$\operatorname{dicting}(\underline{\underline{\sigma}}, \underline{\underline{t}}) \in \arg \min u_{j}(\varphi(c))$. Thus, $t_{i}=-\sum_{l \in N \backslash\{i\}}\left(\sigma_{l}-1\right) c_{l}+\sum_{l \in N \backslash\{i\}}\left(\sigma_{l}^{-i}-\right.$ 1) $c_{l}+\frac{1}{(n-2)} \sum_{l \in N \backslash\{i\}}\left(\sigma_{l}^{-i}-1\right) c_{l}$. 
$c \in \mathbb{R}_{++}^{N}$ and $(\sigma, t) \in \varphi(c)$. By definition of $\varphi^{L}$, we have $\sigma \in \bar{\Sigma}^{*}(c)$. By Theorem 2, for each $i \in N$, we have $t_{i}=-\sum_{l \in F_{i}(\sigma)} c_{l}+\frac{1}{(n-2)} \sum_{j \in N \backslash\{i\}} \sum_{l \in F_{j}\left(\sigma^{-i}\right)} c_{l}$ Thus, $\sum_{i \in N} t_{i}=\sum_{i \in N}\left[-\sum_{l \in F_{i}(\sigma)} c_{l}+\frac{1}{(n-2)} \sum_{j \in N \backslash\{i\}} \sum_{l \in F_{j}\left(\sigma^{-i}\right)} c_{l}\right]$

$$
\begin{aligned}
& =\sum_{i \in N}\left[-\sum_{l \in F_{i}(\sigma)} c_{l}+\frac{1}{(n-2)} \sum_{l \in N \backslash\{i\}}\left(\sigma_{l}^{-i}-1\right) c_{l}\right] \\
& =-\sum_{i \in N} \sum_{l \in F_{i}(\sigma)} c_{l}+\frac{1}{(n-2)} \sum_{i \in N} \sum_{l \in N \backslash\{i\}}\left(\sigma_{l}^{-i}-1\right) c_{l} \\
& =-\sum_{i \in N}\left(\sigma_{i}-1\right) c_{i}+\frac{1}{(n-2)} \sum_{i \in N}(n-2)\left(\sigma_{i}-1\right) c_{i} \\
& =0 .
\end{aligned}
$$

No-envy: ${ }^{15}$ Assume that for each $c \in \mathbb{R}_{++}^{N}$, we have $\varphi(c) \subseteq \varphi^{L}(c)$. Let $c \in \mathbb{R}_{++}^{N},(\sigma, t) \in \varphi(c)$, and $\{i, j\} \subset N$ with $i \neq j$. By definition of $\varphi^{L}$, we have $\sigma \in \bar{\Sigma}^{*}(c)$. By Theorem 2, $t_{i}=\sum_{l \in P_{i}(\sigma)} \frac{\left(\sigma_{l}-1\right)}{(n-2)} c_{l}-\sum_{l \in F_{i}(\sigma)} \frac{\left(n-\sigma_{l}\right)}{(n-2)} c_{l}$ and $t_{j}=\sum_{l \in P_{j}(\sigma)} \frac{\left(\sigma_{l}-1\right)}{(n-2)} c_{l}-\sum_{l \in F_{j}(\sigma)} \frac{\left(n-\sigma_{l}\right)}{(n-2)} c_{l}$. Then, distinguish two cases.

Case 1: $\sigma_{i}<\sigma_{j}$. Let $\delta \in \mathbb{N}$ be such that $\sigma_{j}=\sigma_{i}+\delta$. Then, as by assumption, $1 \leq \sigma_{i}<\sigma_{j} \leq n$, we have $\delta \leq n-\sigma_{i}$. Also, as $\sigma \in \bar{\Sigma}^{*}(c)$, for each $l \in B_{i j}(\sigma)$, we have $c_{i} \geq c_{l} \geq c_{j}$. Thus,

$$
\begin{aligned}
u_{i}\left(\sigma_{i}, t_{i}\right)-u_{i}\left(\sigma_{j}, t_{j}\right) & =\left(-\left(\sigma_{i}-1\right) c_{i}-\sum_{l \in B_{i j}(\sigma)} \frac{\left(n-\sigma_{l}\right)}{(n-2)} c_{l}-\frac{\left(n-\sigma_{j}\right)}{(n-2)} c_{j}\right) \\
& -\left(-\left(\sigma_{j}-1\right) c_{i}+\frac{\left(\sigma_{i}-1\right)}{(n-2)} c_{i}+\sum_{l \in B_{i j}(\sigma)} \frac{\left(\sigma_{l}-1\right)}{(n-2)} c_{l}\right) \\
& =\frac{(n-2) \delta-\left(\sigma_{i}-1\right)}{(n-2)} c_{i}-\frac{(n-1)}{(n-2)} \sum_{l \in B_{i j}(\sigma)} c_{l}-\frac{\left(n-\sigma_{i}-\delta\right)}{(n-2)} c_{j} \\
& \geq\left(\frac{(n-2) \delta-\left(\sigma_{i}-1\right)-(n-1)(\delta-1)-\left(n-\sigma_{i}-\delta\right)}{(n-2)}\right) c_{i} \\
& =0 .
\end{aligned}
$$

Case 2: $\sigma_{i}>\sigma_{j}$. Let $\delta \in \mathbb{N}$ be such that $\sigma_{i}=\sigma_{j}+\delta$. Then, as by assumption, $n \geq \sigma_{i}>\sigma_{j} \geq 1$, we have $\delta \leq n-\sigma_{j}$. Also, as $\sigma \in \bar{\Sigma}^{*}(c)$, for each $l \in B_{j i}(\sigma)$, we have $c_{i} \leq c_{l} \leq c_{j}$. Thus,

$$
\begin{aligned}
u_{i}\left(\sigma_{i}, t_{i}\right)-u_{i}\left(\sigma_{j}, t_{j}\right) & =\left(-\left(\sigma_{i}-1\right) c_{i}+\frac{\left(\sigma_{j}-1\right)}{(n-2)} c_{j}+\sum_{l \in B_{j i}(\sigma)} \frac{\left(\sigma_{l}-1\right)}{(n-2)} c_{l}\right) \\
& -\left(-\left(\sigma_{j}-1\right) c_{i}-\sum_{l \in B_{j i}(\sigma)} \frac{\left(n-\sigma_{l}\right)}{(n-2)} c_{l}-\frac{\left(n-\sigma_{i}\right)}{(n-2)} c_{i}\right) \\
& =\frac{-(n-2) \delta+\left(n-\sigma_{j}-\delta\right)}{(n-2)} c_{i}+\frac{(n-1)}{(n-2)} \sum_{l \in B_{j i}(\sigma)} c_{l}+\frac{\left(\sigma_{j}-1\right)}{(n-2)} c_{j} \\
& \geq\left(\frac{-(n-2) \delta+\left(n-\sigma_{j}-\delta\right)+(n-1)(\delta-1)+\left(\sigma_{j}-1\right)}{(n-2)}\right) c_{i} \\
& =0 .
\end{aligned}
$$

Strategy-proofness: Assume that for each $c \in \mathbb{R}_{++}^{N}$, we have $\varphi(c) \subseteq \varphi^{L}(c)$. By definition, (i) for each $c \in \mathbb{R}_{++}^{N}$ and each $(\sigma, t) \in \varphi(c)$, we have $\sigma \in \bar{\Sigma}^{*}(c)$. By Theorem 2, there is $h \in H$ such that (ii) for each $c \in \mathbb{R}_{++}^{N}$, each $(\sigma, t) \in \varphi(c)$, and each $i \in N$, we have $t_{i}=-\sum_{l \in N \backslash\{i\}}\left(\sigma_{l}-1\right) c_{l}+h_{i}\left(c_{-i}\right)$. Let $c \in \mathbb{R}_{++}^{N}, i \in N, c_{i}^{\prime} \in \mathbb{R}_{++},(\sigma, t) \in \varphi(c)$, and $\left(\sigma^{\prime}, t^{\prime}\right) \in \varphi\left(c_{i}^{\prime}, c_{-i}\right)$. By $(\mathbf{i})$, $-\sum_{l \in N}\left(\sigma_{l}-1\right) c_{l} \geq-\sum_{l \in N}\left(\sigma_{l}^{\prime}-1\right) c_{l}$. Thus, $-\left(\sigma_{i}-1\right) c_{i}-\sum_{l \in N \backslash\{i\}}\left(\sigma_{l}-1\right) c_{l}+$ $h_{i}\left(c_{-i}\right) \geq-\left(\sigma_{i}^{\prime}-1\right) c_{i}-\sum_{l \in N \backslash\{i\}}\left(\sigma_{l}^{\prime}-1\right) c_{l}+h_{i}\left(c_{-i}\right)$. By (ii), $u_{i}\left(\sigma_{i}, t_{i}\right) \geq u_{i}\left(\sigma_{i}^{\prime}, t_{i}^{\prime}\right)$.

$\overline{{ }^{15} \mathrm{~A} \text { rule }} \varphi$ to satisfy Pareto-efficiency and no-envy if and only if for each $c \in \mathbb{R}_{++}^{N}$ and each $(\sigma, t) \in \varphi(c)$, we have $\sigma \in \Sigma^{*}(c), \sum_{i \in N} t_{i}=0$, and for each $\{i, j\} \subset N$, if $\sigma_{j}=\sigma_{i}+1$, then $c_{i} \geq t_{j}-t_{i} \geq c_{j}$ (Chun, 2006b). An alternative proof consists in proving that EDPP rules satisfy this condition. Rules in Suijs (1996) satisfy it (Katta and Sethuraman, 2006). Thus, by Theorem 2, so do EDPP rules. 
This holds for each $(\sigma, t) \in \varphi(c)$ and each $\left(\sigma^{\prime}, t^{\prime}\right) \in \varphi\left(c_{i}^{\prime}, c_{-i}\right)$. Thus, $\varphi(c) R_{i}\left(c_{i}\right) \varphi\left(c_{i}^{\prime}, c_{-i}\right)$.

Statement 3: Assume that $\varphi$ satisfies the axioms of Theorem 3.3. Let $c \in \mathbb{R}_{++}^{N}$ and $(\sigma, t) \in \varphi(c)$. By Pareto-efficiency, $\sigma \in \bar{\Sigma}^{*}(c)$. By Theorem 1, Pareto-efficiency and strategy-proofness imply that there is $\{\underline{h}, \bar{h}\} \subset H$ such that for each $i \in N$, if $(\underline{\sigma}, \underline{t}) \in \arg \min u_{i}(\varphi(c))$, then $\underline{t}_{i}=-\sum_{l \in N \backslash\{i\}}\left(\underline{\sigma}_{l}-1\right) c_{l}+\underline{h}_{i}\left(c_{-i}\right)$ and if $(\bar{\sigma}, \bar{t}) \in \arg \max u_{i}(\varphi(c))$, then $\bar{t}_{i}=-\sum_{l \in N \backslash\{i\}}\left(\bar{\sigma}_{l}-1\right) c_{l}+\bar{h}_{i}\left(c_{-i}\right)$. By symmetry, for each $\{i, j\} \subset N$, if $c_{-i}=c_{-j}$, then $\underline{h}_{i}\left(c_{-i}\right)=\underline{h}_{j}\left(c_{-j}\right)$ and $\bar{h}_{i}\left(c_{-i}\right)=\bar{h}_{j}\left(c_{-j}\right)$. Thus, for each $\{i, j\} \subset N$, if $c_{i}=c_{j}$, then $\underline{h}_{i}\left(c_{-i}\right)=\underline{h}_{j}\left(c_{-j}\right)$ and $\bar{h}_{i}\left(c_{-i}\right)=\bar{h}_{j}\left(c_{-j}\right)$. By Statement 1's step process and Pareto-efficiency of queues, for each $i \in N$, we have $t_{i}=-\sum_{l \in F_{i}(\sigma)} c_{l}+\frac{1}{(n-2)} \sum_{j \in N \backslash\{i\}} \sum_{l \in F_{j}\left(\sigma^{-i}\right)} c_{l}$. Thus, $\varphi(c) \subseteq \varphi^{L}(c)$. By symmetry, $\varphi(c)=\varphi^{L}(c)$.

Statement 4: Assume that for each $c \in \mathbb{R}_{++}^{N}$, we have $\varphi(c)=\varphi^{L}(c)$. By Theorem 3.2, $\varphi$ satisfies Pareto-efficiency and strategy-proofness. Also, $\varphi$ does not depend on agents' names. In particular, $t_{i}$ has the same structure for each $i \in N$. Thus, $\varphi$ satisfies anonymity.

Nota 2 By Theorem 3, a single-valued rule satisfies Pareto-efficiency, equal treatment of equals in welfare, and strategy-proofness if and only if it is a single-valued EDPP rule. Thus, in Theorem 3, we prove that in all cases, even in those where, for any reasons (political, social, practical, ...) one imposes to systematically select only one alternative and hence forces to make arbitrary choices, at the expense of basic equity considerations, there is a unique transfers list. One obtains it considering each pair of agents in turn, making each agent in the pair pay the cost she imposes on the pair, and distributing the sum of these two payments equally among the others.

Finally, Pareto-efficiency, no-envy, and strategy-proofness are independent of one another. Rules such that for each $c \in \mathbb{R}_{++}^{N}$, if $(\sigma, t)$ is selected, then $\sigma \in \bar{\Sigma}^{*}(c)$ and for $\alpha \in \mathbb{R}_{++}^{N}$ such that if $i \in N$ with $\sigma_{i} \neq 1$ and $\{j, k\} \subset N$ are such that $\sigma_{j}=\sigma_{i}-1$ and $\sigma_{k}=\sigma_{i}+1$, then $\alpha_{i} \in\left[c_{j}, c_{k}\right]$ and $t_{i}=\sum_{l \in P_{i}(\sigma) \cup\{i\}} \alpha_{l}$ and if $i \in N$ with $\sigma_{i}=1$, then $t_{i}=\alpha_{i}$ and $\sum_{l \in N} t_{l}=0$, satisfy all axioms, but strategy-proofness (Chun, 2006b; Katta and Sethuraman, 2006). Groves rules associated with $h \in H$ such that for each $c \in \mathbb{R}_{++}^{N}$ and for $\lambda \in \mathbb{R}$ with $\lambda \neq 0$, if $(\sigma, t)$ is selected, $h_{1}=\sum_{l \in N \backslash\{1\}}\left(\sigma_{l}^{-1}-1\right) c_{l}+\frac{1}{n-2} \sum_{l \in N \backslash\{1\}}\left(\sigma_{l}^{-1}-1\right) c_{l}+\lambda$ and for each $i \in N \backslash\{1\}$, we have $h_{i}=\sum_{l \in N \backslash\{i\}}\left(\sigma_{l}^{-i}-1\right) c_{i}+\frac{1}{n-2} \sum_{l \in N \backslash\{i\}}\left(\sigma_{l}^{-i}-\right.$ 1) $c_{l}-\frac{\lambda}{(n-1)}$ satisfy all axioms, but no-envy. Groves rules associated with $h \in H$ such that for each $c \in \mathbb{R}_{++}^{N}$ and for $\lambda \in \mathbb{R}_{++}$, if $(\sigma, t)$ is selected, then for each $i \in N$, we have $h_{i}=\sum_{l \in N \backslash\{i\}}\left(\sigma_{l}^{-i}-1\right) c_{i}+\frac{1}{n-2} \sum_{l \in N \backslash\{i\}}\left(\sigma_{l}^{-i}-1\right) c_{l}-\lambda$ satisfy all axioms, but Pareto-efficiency. 
Also, Pareto-efficiency, anonymity, and strategy-proofness are independent of one another. The rule that selects all Pareto-efficient queues and sets each agent's transfer equal to the Shapley value of the associated coalitional game, where the worth of a coalition is the minimum possible sum of its members waiting costs (Maniquet, 2003), satisfies all axioms, but strategy-proofness. Proper subcorrespondences of a rule that is the union of all the single-valued rules that are Groves rules associated with $h \in H$ and that satisfy balancedness, satisfies all axioms, but anonymity. Any rule such that for each $c \in \mathbb{R}_{++}^{N}$ and for $\lambda \in \mathbb{R}_{+}$, we have that $(\sigma, t)$ is selected if and only if $\sigma \in\{1,2, \ldots, n\}^{N}$ and for each $i \in N$, we have $t_{i}=-\lambda$, satisfy all axioms, but Pareto-efficiency.

\section{Extensions}

From the previous sections, we know that the problems we study are among the few allocation problems, in which Pareto-efficiency, weak equity axioms as equal treatment of equals in welfare or symmetry, and strategy-proofness are compatible. The natural step now is to determine if this compatibility extends to other problems and when it does, if the appropriate generalization of the rule we introduce, is still a desirable rule.

First, assume that agents enjoy some benefit, once they receive the service. We may exclude agents, not force them to participate. In problems, in which these axioms are compatible, the appropriate generalization of the LEDPP rule remains the only rule satisfying them. Further, it guarantees each agent voluntarily participate to the rule. ${ }^{16}$ The intuition is simple. As Pareto-efficiency may impose excluding an agent when considering $N$, not when considering subsets of $N$, we cannot always express the sum of the costs each agent imposes on the others, as the sum of the costs each agent imposes on each element of a partition of the others. A contrario, we can, if Pareto-efficiency imposes excluding an agent when considering $N$ if and only if it does when considering any pair of agents including her.

Second, assume that agents may differ in processing times. As one easily checks the accuracy of these processing times' announcements once one serves the agents, it is natural to assume that only information on waiting costs is private. The appropriate generalization of the LEDPP rule still satisfies these axioms.

Indeed, when agents have equal unit waiting costs and processing times, to treat agents equally, a desirable rule selects queues and sets transfers in the spirit of the LEDPP rule. When agents differ in unit waiting costs, not in

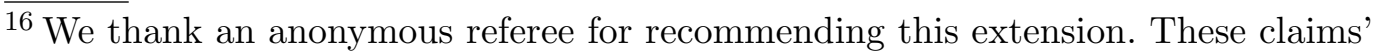
proofs, using Theorem 3's logic, are available to the reader upon request to us.
} 
processing times, to give agents incentives to reveal their waiting cost, it still selects queues and sets transfers in the spirit of this rule. When agents differ in unit waiting costs and processing times, it still selects all Pareto-efficient queues and it sets balanced transfers such that for each agent and each bundle that maximizes or minimizes her utility, her transfer is equal to the others' total waiting cost plus an amount only depending on these agents' unit waiting costs. Setting them in the spirit of the LEDPP rule is an obvious example.

Finally, assume that instead of organizing queues, we assign objects, tasks, time shifts, etc. For instance, think of allocation problems of student houses. Students value a house according to how close it is to the campus. This is an assignment problem of at most one indivisible good per agent, in which agents rank goods identically. As queueing problems are such problems, our results apply. Efficiency, equity, and incentive compatibility need not be simultaneously possible. Yet, in problems, in which they are, the appropriate generalization of the LEDPP rule satisfies them, if it is not the only one.

\section{Concluding comments}

Our objective was to identify allocation rules for queueing problems satisfying efficiency, equity, and incentive compatibility criteria simultaneously. We proved that on the domain of linear preferences in positions and transfers, the Largest Equally Distributed Pairwise Pivotal (LEDPP) rule is the only such rule. It is characterized by Pareto-efficiency, equal treatment of equals in welfare, symmetry, and strategy-proofness. Further, it satisfies stronger equity and incentive compatibility criteria.

Since the day that humans gathered into societies, there have been queues (Hall, 1991). In particular situations, one may hardly equate the costs from having to wait, to the monetary costs waiting almost inescapably implies. Think of a patient listed for an organ transplant. Yet, in many cases, agents value their waiting costs in such monetary terms. Obvious examples are costs that continue running while waiting (wages, inventory costs, legal constraints, telephone charges, "burned" gaz, etc.) or opportunity costs (wages, shortfalls, etc.). As Hall (1991) puts it, every minute that an employee spends waiting for another department and every minute that a job spends waiting to be processed is money wasted. Such especially short term problems involving cashflows are frequent in daily lifes of individuals, businesses, and institutions. One then approximates waiting costs with a linear function of time. ${ }^{17}$

Throughout our analysis, we had the concern to a priori impose the least to

\footnotetext{
${ }^{17}$ As agents discount future, those exponentially increase with time in the long run.
} 
have stronger results. First, we considered any rules, i.e. single-valued or not. Doing so, we made our study more general in the following sense. It provides answers even for those cases where, for any reasons (political, social, practical, ...) one imposes to systematically select only one alternative and hence, forces to make arbitrary choices, at the expense of basic equity considerations.

Second, the equity and incentive compatibility axioms we imposed are weak. These may hence encompass extreme positions. For instance, if agents have exactly the same costs, our equity axioms require to treat these agents equally, whereas if agents have even only slightly different costs, they do not require anything. The underlying idea was to first establish what happens when we impose weak axioms. Only then, we may strenghten them and instead, impose axioms that we find as appealing, if not more, as no-envy, anonymity, or the incentive compatibility axiom according to which each agent always finds any bundle she receives when revealing her unit waiting cost at least as desirable as any bundle she receives when misrepresenting it.

Doing so, we determined each axiom's role and hence, we made the axiomatic analysis more transparent. Eventually, we proved that in the queueing problems we studied, one does not need to impose stronger equity or incentive compatibility axioms as they are "for free". Thus, a priori requiring the least, we made our characterizations stronger in the following sense. When such results hold for weak axioms, they hold for stronger axioms, not inversely.

Our analysis formalized solutions as allocation rules. These associate with each problem a non-empty set of allocations. As explained when defining strategyproofness, selecting a multi-valued set of allocations is a first step. By definition, the allocations it contains are mutually exclusive. In fine, only one materializes. The interpretation we gave is that eventually, a random device selects one of these allocations as the final outcome. An alternative formalization of solutions, in which chance may play a role, is the one of decision schemes. These associate with each problem a lottery on the set of allocations. One may reformulate all our results in terms of decision schemes. ${ }^{18} \mathrm{We}$ used the allocation rule formalization as it offers more possible interpretations.

We draw three lessons from our results. First, the problems we studied are among the few allocation problems, in which Pareto-efficiency, weak equity

\footnotetext{
${ }^{18}$ In particular, only $L E D P P$ schemes, i.e. shemes such that for each problem, an allocation is in the support selected for this problem if and only if it is in the set selected by the LEDPP rule for this problem, satisfy the efficiency, equity, and incentive compatibility axioms we imposed. There is no need for further assumptions regarding agents' uncertainty aversions, especially that agents are expected utility maximizers. A stronger version of symmetry requires all symmetric allocations with respect to equal agents to be equally probable. Then, only the uniform LEDPP scheme satisfies these axioms.
} 
axioms as equal treatment of equals in welfare or symmetry, and strategyproofness are compatible. In other problems, these axioms need not be simultaneously possible. Yet, in problems, in which they are, the appropriate generalization of the LEDPP rule satisfies them, if it is not the only one.

Second, while Pareto-efficiency and strategy-proofness leave us with a large class of rules, adding a weak equity axiom as equal treatment of equals in welfare or symmetry, imposes a unique transfers list. To underline this contrast, we identified the class of non-single-valued rules that Pareto-efficiency of queues and strategy-proofness recommend. We proved that as in the singlevalued case, this class is large. It contains the rules that select Pareto-efficient queues and set transfers in the spirit of Groves (1973). This result holds in other problems, provided the domain of quasi-linear preferences is rich enough.

Third, in the queueing problems we studied, simply requiring to treat equal agents equally in addition to Pareto-efficiency and strategy-proofness, guarantees further basic equity criteria. It prevents agents from envying one another. It prevents agents' names to matter. It guarantees each agent with a minimal welfare level. Indeed, in allocation problems of at most one indivisible good per agent, no-envy implies the identical-preferences lower bound, i.e. each agent should find her bundle at least as desirable as any bundle Pareto-efficiency and equal treatment of equals in welfare recommend when the others have her preferences (Beviá, 1996). It also satisfies other equity criteria specific to queueing problems (Katta and Sethuraman, 2006).

In allocation problems of private goods, equal treatment of equals in welfare and coalition strategy-proofness, i.e. no coalition should gain by simultaneously misrepresenting their preferences, imply no-envy (Moulin, 1993). In general public decision-making problems with strictly monotonically closed preferences, equal treatment of equals in welfare, strategy-proofness, and nonbossiness, i.e. if a change in an agent's waiting cost does not alter her bundle, it should not alter other agents' bundles, imply no-envy (Fleurbaey and Maniquet, 1997). These results do not apply to queueing problems. Pareto-efficiency is incompatible with coalition strategy-proofness (Kayı and Ramaekers, 2006; Mitra and Mutuswami, 2008), and with strategy-proofness and non-bossiness (Kayı and Ramaekers, 2006).

For further equity axioms, as those relative to changes in the set of agents or waiting costs, one must know agents' waiting costs. Indeed, on the domain of linear preferences in positions and transfers, only rules that select Paretoefficient queues and set each agent's transfer equal to the Shapley value of some associated coalitional game, satisfy these axioms, and the efficiency and equity axioms we imposed (Maniquet, 2003; Chun, 2006a; Katta and Sethuraman, 2006). Yet, such rules do not satisfy strategy-proofness. Further, these axioms, Pareto-efficiency, and no-envy are incompatible (Chun, 2006b). 


\section{References}

Barberá, S., 1977. The manipulation of social choice mechanisms that do not leave too much chance. Econometrica 45, 1573-1588.

Barberá, S., Dutta, B., Sen, A., 2001. Strategyproof social choice correspondences. J. Econ. Theory 101, 374-394.

Beviá, C., 1996. Identical preferences lower bound and consistency in economies with indivisible goods. Soc. Choice Welfare 13, 113-126.

Bossert, W., 1989. On the extension of preferences over a set to the power set: An axiomatic characterization of a quasi-ordering. J. Econ. Theory 49, 84-92.

Ching, S., 1994. An alternative characterization of the uniform rule. Soc. Choice Welfare 11, 131-135.

Ching, S., Zhou, L., 2002. Multi-valued strategy-proof social choice rules. Soc. Choice Welfare 19, 569-580.

Chun, Y., 2006a. A pessimistic approach to the queueing problem. Math. Soc. Sci. 51, 171-181.

Chun, Y., 2006b. No-envy in queueing problems. Econ. Theory 29, 151-162.

Clarke, E., 1971. Multipart pricing of public goods. Public Choice 8, 19-33.

Duggan, J., Schwartz, T., 2000. Strategic manipulability without resoluteness of shared beliefs: Gibbard-Satterthwaite generalized. Soc. Choice Welfare 17, 85-93.

Feldman, A., 1979. Manipulation and the Pareto rule. J. Econ. Theory 21, 473-482.

Fishburn, P., 1972. Even-chance lotteries in Social choice theory. Theory and Decision 3, 18-40.

Fleurbaey, M., Maniquet, F., 1996. Implementability and horizontal equity imply no-envy. Econometrica 65, 1215-1220. 
Gärdenfors, P., 1976. Manipulation of social choice functions. J. Econ. Theory $13,217-228$.

Gärdenfors, P., 1979. On definitions of manipulation of social choice functions. In: Laffont, J.-J. (Ed.), Aggregation and Revelation of Preferences, NorthHolland Publishing Company, Amsterdam, pp. 29-36.

Gibbard, A., 1973. Manipulation of voting schemes. Econometrica 41, 617631.

Green, J., Laffont, J-J., 1977. Characterization of satisfactory mechanisms for the revelation of preferences for public goods. Econometrica 45, 727-738.

Groves, T., 1973. Incentives in teams. Econometrica 41, 617-631.

Hall, R. W., 1991. Queueing methods: For services and manufacturing. Prentice Hall, Upper Saddle River.

Holmström, B., 1979. Groves' scheme on restricted domains. Econometrica 47, 1137-1144.

Jackson, M. O., 1992. Implementation in undominated strategies: A look at bounded mechanisms. Rev. Econ. Stud. 59, 757-775.

Kannai, Y., Peleg, B. 1984. A note on the extension of an order on a set to the power set. J. Econ. Theory 32, 172-175.

Katta, A., Sethuraman, J., 2006. Cooperation in queues. Mimeo, Columbia University, New York.

Kayı, Ç., Ramaekers, E., 2006. There is no efficient and coalitional strategyproof allocation rules in sequencing problems. Mimeo, Université catholique de Louvain, CORE, Louvain-la-Neuve.

Kelly, J. S., 1977. Strategy-proofness and social choice functions without single-valuedness. Econometrica 45, 439-446.

Maniquet, F., 2003. A characterization of the Shapley value in queueing problems. J. Econ. Theory 109, 90-103. 
Maniquet, F., Sprumont, Y., 1999. Efficient strategy-proof allocation functions in linear production economies. Econ. Theory 14, 583-595.

Mitra, M., 2001. Mechanism design in queueing problems. Econ. Theory 17, $277-305$.

Mitra, M., 2002. Achieving the first best in sequencing problems. Rev. Econ. Design 7, 75-91.

Mitra, M., Sen, A., 1998. Dominant strategy implementation of first best public decision. Mimeo, Indian Statistical Institute, New Delhi.

Mitra, M., Mutuswami, S., 2008. Group strategyproofness in queueing models. Mimeo, Indian Statistical Institute, Kolkata.

Moulin, H., 1980. On strategy-proofness and single peakedness. Public Choice $35,437-455$.

Moulin, H., 1993. On the fair and coalition strategy-proof allocation of private goods. In: Binmore et al. (Eds.), Frontiers in Game Theory. M.I.T. press, Cambridge, pp. 151-163.

Pattanaik, P. K., 1973. On the stability of sincere voting situations. J. Econ. Theory $6,558-574$.

Satterthwaite, M. A., 1975. Strategy-proofness and Arrow's conditions: Existence and correspondence theorems for voting procedures and social welfare functions. J. Econ. Theory 10, 187-217.

Sprumont, Y., 1991. The division problem with single-peaked preferences: A characterization of the uniform allocation rule. Econometrica 59, 509-519.

Suijs, J., 1996. On incentive compatibility and budget balancedness in public decision making. Econ. Design 2, 193-209. 


\section{Recent titles \\ CORE Discussion Papers}

2008/45. Taoufik BOUEZMARNI, Jeroen V.K. ROMBOUTS and Abderrahim TAAMOUTI. Asymptotic properties of the Bernstein density copula for dependent data.

2008/46. Joe THARAKAN and Jean-Philippe TROPEANO. On the impact of labor market matching on regional disparities.

2008/47. Shin-Huei WANG and Cheng HSIAO. An easy test for two stationary long processes being uncorrelated via AR approximations.

2008/48. David DE LA CROIX. Adult longevity and economic take-off: from Malthus to Ben-Porath.

2008/49. David DE LA CROIX and Gregory PONTHIERE. On the Golden Rule of capital accumulation under endogenous longevity.

2008/50. Jean J. GABSZEWICZ and Skerdilajda ZANAJ. Successive oligopolies and decreasing returns.

2008/51. Marie-Louise LEROUX, Pierre PESTIEAU and Grégory PONTHIERE. Optimal linear taxation under endogenous longevity.

2008/52. Yuri YATSENKO, Raouf BOUCEKKINE and Natali HRITONENKO. Estimating the dynamics of R\&D-based growth models.

2008/53. Roland Iwan LUTTENS and Marie-Anne VALFORT. Voting for redistribution under desertsensitive altruism.

2008/54. Sergei PEKARSKI. Budget deficits and inflation feedback. 2008/55. Raouf BOUCEKKINE, Jacek B. KRAWCZYK and Thomas VALLEE. Towards an understanding of tradeoffs between regional wealth, tightness of a common environmental constraint and the sharing rules.

2008/56. Santanu S. DEY. A note on the split rank of intersection cuts.

2008/57. Yu. NESTEROV. Primal-dual interior-point methods with asymmetric barriers.

2008/58. Marie-Louise LEROUX, Pierre PESTIEAU and Gregory PONTHIERE. Should we subsidize longevity?

2008/59. J. Roderick McCRORIE. The role of Skorokhod space in the development of the econometric analysis of time series.

2008/60. Yu. NESTEROV. Barrier subgradient method.

2008/61. Thierry BRECHET, Johan EYCKMANS, François GERARD, Philippe MARBAIX, Henry TULKENS and Jean-Pascal VAN YPERSELE. The impact of the unilateral EU commitment on the stability of international climate agreements.

2008/62. Giorgia OGGIONI and Yves SMEERS. Average power contracts can mitigate carbon leakage.

2008/63. Jean-Sébastien TANCREZ, Philippe CHEVALIER and Pierre SEMAL. A tight bound on the throughput of queueing networks with blocking.

2008/64. Nicolas GILLIS and François GLINEUR. Nonnegative factorization and the maximum edge biclique problem.

2008/65. Geir B. ASHEIM, Claude D'ASPREMONT and Kuntal BANERJEE. Generalized timeinvariant overtaking.

2008/66. Jean-François CAULIER, Ana MAULEON and Vincent VANNETELBOSCH. Contractually stable networks.

2008/67. Jean J. GABSZEWICZ, Filomena GARCIA, Joana PAIS and Joana RESENDE. On Gale and Shapley 'College admissions and stability of marriage'.

2008/68. Axel GAUTIER and Anne YVRANDE-BILLON. Contract renewal as an incentive device. An application to the French urban public transport sector.

2008/69. Yuri YATSENKO and Natali HRITONENKO. Discrete-continuous analysis of optimal equipment replacement.

2008/70. Michel JOURNÉE, Yurii NESTEROV, Peter RICHTÁRIK and Rodolphe SEPULCHRE. Generalized power method for sparse principal component analysis.

2008/71. Toshihiro OKUBO and Pierre M. PICARD. Firms' location under taste and demand heterogeneity.

2008/72. Iwan MEIER and Jeroen V.K. ROMBOUTS. Style rotation and performance persistence of mutual funds. 


\section{Recent titles}

\section{CORE Discussion Papers - continued}

2008/73. Shin-Huei WANG and Christian M. HAFNER. Estimating autocorrelations in the presence of deterministic trends.

2008/74. Yuri YATSENKO and Natali HRITONENKO. Technological breakthroughs and asset replacement.

2008/75. Julio DÁVILA. The taxation of capital returns in overlapping generations economies without financial assets.

2008/76. Giorgia OGGIONI and Yves SMEERS. Equilibrium models for the carbon leakage problem.

2008/77. Jean-François MERTENS and Anna RUBINCHIK. Intergenerational equity and the discount rate for cost-benefit analysis.

2008/78. Claire DUJARDIN and Florence GOFFETTE-NAGOT. Does public housing occupancy increase unemployment?

2008/79. Sandra PONCET, Walter STEINGRESS and Hylke VANDENBUSSCHE. Financial constraints in China: firm-level evidence.

2008/80. Jean GABSZEWICZ, Salome GVETADZE, Didier LAUSSEL and Patrice PIERETTI. Pubic goods' attractiveness and migrations.

2008/81. Karen CRABBE and Hylke VANDENBUSSCHE. Are your firm's taxes set in Warsaw? Spatial tax competition in Europe.

2008/82. Jean-Sébastien TANCREZ, Benoît ROLAND, Jean-Philippe CORDIER and Fouad RIANE. How stochasticity and emergencies disrupt the surgical schedule.

2008/83. Peter RICHTÁRIK. Approximate level method.

2008/84. Çağatay KANI and Eve RAMAEKERS. Characterizations of Pareto-efficient, fair, and strategyproof allocation rules in queueing problems.

\section{Books}

Y. POCHET and L. WOLSEY (eds.) (2006), Production planning by mixed integer programming. New York, Springer-Verlag.

P. PESTIEAU (ed.) (2006), The welfare state in the European Union: economic and social perspectives. Oxford, Oxford University Press.

H. TULKENS (ed.) (2006), Public goods, environmental externalities and fiscal competition. New York, Springer-Verlag.

V. GINSBURGH and D. THROSBY (eds.) (2006), Handbook of the economics of art and culture. Amsterdam, Elsevier.

J. GABSZEWICZ (ed.) (2006), La différenciation des produits. Paris, La découverte.

L. BAUWENS, W. POHLMEIER and D. VEREDAS (eds.) (2008), High frequency financial econometrics: recent developments. Heidelberg, Physica-Verlag.

P. VAN HENTENRYCKE and L. WOLSEY (eds.) (2007), Integration of AI and OR techniques in constraint programming for combinatorial optimization problems. Berlin, Springer.

\section{CORE Lecture Series}

C. GOURIÉROUX and A. MONFORT (1995), Simulation Based Econometric Methods.

A. RUBINSTEIN (1996), Lectures on Modeling Bounded Rationality.

J. RENEGAR (1999), A Mathematical View of Interior-Point Methods in Convex Optimization.

B.D. BERNHEIM and M.D. WHINSTON (1999), Anticompetitive Exclusion and Foreclosure Through Vertical Agreements.

D. BIENSTOCK (2001), Potential function methods for approximately solving linear programming problems: theory and practice.

R. AMIR (2002), Supermodularity and complementarity in economics.

R. WEISMANTEL (2006), Lectures on mixed nonlinear programming. 